\title{
Global-scale remote sensing of water isotopologues in the troposphere: representation of first-order isotope effects
}

\author{
S. J. Sutanto ${ }^{1,2}$, G. Hoffmann ${ }^{1,3}$, R. A. Scheepmaker ${ }^{4}$, J. Worden ${ }^{5}$, S. Houweling ${ }^{1,4}$, K. Yoshimura ${ }^{6}$, I. Aben , and $^{4}$ \\ T. Röckmann ${ }^{1}$ \\ ${ }^{1}$ Institute for Marine and Atmosphere Research Utrecht, University of Utrecht, Princetonplein 5, 3584CC, Utrecht, the \\ Netherlands \\ ${ }^{2}$ Research Center for Water Resources, Ministry of Public Works, Jl. Ir. H. Djuanda 93, Bandung 40135, Indonesia \\ ${ }^{3}$ Laboratorie des Sciences du Climat et de l'Environnement, LSCE-Orme, point courrier 129, CEA-Orme des Merisiers, 91 \\ GIF-SUR-YVETTE CEDEX, France \\ ${ }^{4}$ SRON Netherlands Institute for Space Research, Sorbonnelaan 2, 3584CA, Utrecht, the Netherlands \\ ${ }^{5}$ Jet Propulsion Laboratory/California Institute of technology, Pasadena, California, USA \\ ${ }^{6}$ Atmosphere and Ocean Research Institute, University of Tokyo, Kashiwa, Japan
}

Correspondence to: S. J. Sutanto (s.j.sutanto@uu.nl)

Received: 16 May 2014 - Published in Atmos. Meas. Tech. Discuss.: 9 September 2014

Revised: 29 January 2015 - Accepted: 29 January 2015 - Published: 3 March 2015

\begin{abstract}
Over the last decade, global-scale data sets of atmospheric water vapor isotopologues (HDO) have become available from different remote sensing instruments. Due to the observational geometry and the spectral ranges that are used, few satellites sample water isotopologues in the lower troposphere, where the bulk of hydrological processes within the atmosphere take place. Here, we compare three satellite HDO data sets, two from the Tropospheric Emission Spectrometer (TES retrieval version 4 and 5) and one from SCIAMACHY (SCanning Imaging Absorption spectroMeter for Atmospheric CHartographY), with results from the atmospheric global circulation model ECHAM4 (European Centre HAMburg 4). We examine a list of known isotopologue effects to qualitatively benchmark the various observational data sets. TES version 5 (TESV5), TES version 4 $\left(\mathrm{TES}_{\mathrm{V} 4}\right)$, SCIAMACHY, ECHAM, and ECHAM convolved with averaging kernels of TES version $5\left(\mathrm{ECHAM}_{\mathrm{AK} 5}\right)$ successfully reproduced a number of established isotopologue effects such as the latitude effect, the amount effect, and the continental effect. The improvement of TES $\mathrm{V}_{5}$ over TES $\mathrm{V} 4$ is confirmed by the steeper latitudinal gradient at higher latitudes in agreement with SCIAMACHY. Also the representation of other features of the water isotopologue cycle, such as the seasonally varying signal in the tropics due to the movement of the Intertropical Convergence Zone (ITCZ), is im-
\end{abstract}

proved in TESV5 and SCIAMACHY compared to TES $\mathrm{V}_{4}$. A known humidity bias due to the cross correlation of $\mathrm{H}_{2} \mathrm{O}$ and HDO measurements, which is of particular importance for instruments with low sensitivity close to the surface, was analyzed by applying either a humidity bias correction or a suitable a posteriori analysis. We suggest that the qualitative and quantitative tests carried out in this study could become benchmark tests for evaluation of future satellite isotopologue data sets.

\section{Introduction}

Heavy isotopologues of atmospheric water (principally HDO and $\mathrm{H}_{2}^{18} \mathrm{O}$ ) are important tracers that are widely used to derive information on moisture recycling (Worden et al., 2007; Risi et al., 2013), cloud physics (Webster and Heymsfield, 2003), troposphere-stratosphere exchange (Kuang et al., 2003; Moyer et al., 1996; Steinwagner et al., 2010), climate studies (Gedzelman et al., 2003; Lawrence et al., 2002), and paleoclimate (Jouzel et al., 1997; Field, 2010). Equilibrium and kinetic isotope effects in the hydrological cycle associated mainly with evaporation, condensation, and diffusion - can be measured in the laboratory with high precision. 
Due to the potential of these measurements for evaluating hydrological cycle processes, the Global Network of Isotopes in Precipitation (GNIP) has supported the evaluation and storage of precipitation isotope measurements (Aggarwal et al., 2007). Compared to this global-scale international activity directed at precipitation, only very few measurements have been directed at measuring water vapor, because of the logistical effort required for sampling water vapor using mechanical cold trap devices (e.g., Ehhalt et al., 1989; Franz and Röckmann, 2005. Nevertheless, the bulk of water in the atmosphere is in the vapor phase, and the liquid fraction of atmospheric water amounts only to a very small percentage of the total water.

With the development of faster and more robust in situ measurement methods for water vapor isotopologues, the number of measurements has been strongly increasing in recent years. Available techniques include tunable diode laser (TDL) absorption spectroscopy (Lee et al., 2005), in situ FTIR (Fourier transform infrared) (Griffith et al., 2006), cavity ring-down spectroscopy (Gupta et al., 2009), and integrated cavity output spectroscopy (Wang et al., 2009; Sturm and Knohl, 2010). These techniques are now operational at several ground sites and have been installed on mobile platforms like balloons, ships, and aircraft. In addition, groundbased FTIR remote sensing observations are made within the MUSICA/NDACC (MUltiplatform remote Sensing of Isotopologues for investigating the Cycle of Atmospheric water/Network for the Detection of Atmospheric Composition Change; Schneider et al., 2006, 2012) and TCCON (Total Carbon Column Observing Network; Wunch et al., 2010) networks.

In addition, global water isotopologue data have become available using remote sensing techniques installed onboard satellite platforms: the Interferometric Monitor for Greenhouse Gases (IMG) on ADEOS (Zakharov et al., 2004; Herbin et al., 2007), the Tropospheric Emission Spectrometer (TES) on Aura (Worden et al., 2006), the Michelson Interferometer for Passive Atmospheric Sounding (MIPAS) on Envisat (Payne et al., 2007; Steinwagner et al., 2007, 2010; Lossow et al., 2011), the SCanning Imaging Absorption spectroMeter for Atmospheric CHartography (SCIAMACHY) on Envisat (Frankenberg et al., 2009; Scheepmaker et al., 2013), the Infrared Atmospheric Sounding Interferometer (IASI) on Metop (Herbin et al., 2009; Lacour et al., 2012; Schneider and Hase, 2011; Wiegele et al., 2014), and the Greenhouse gases Observing SATellite (GOSAT) launched by the Japanese Space Agency in January 2009 (Boesch et al., 2013; Frankenberg et al., 2013). These instruments are sensitive to different parts of the atmosphere. For example, MIPAS has significant sensitivity to the water vapor isotope distribution in the upper troposphere and stratosphere as it is a limb thermal infrared sounder, TES is a nadir-looking thermal infrared sounder with high sensitivity from 850 to $500 \mathrm{hPa}$ (version 4) or from 900 to $350 \mathrm{hPa}$ (version 5), while SCIAMACHY measurements are sensitive to the total atmospheric column as it is a nadir-looking shortwave infrared (SWIR) sensor.

Global-scale water isotopologue measurements also provide invaluable information to validate isotope-enabled atmospheric general circulation models (Iso-AGCMs), such as ECHAM (European Centre HAMburg; Hoffmann et al., 1998; Werner et al., 2011), GISS-E (Goddard Institute for Space Studies; Schmidt et al., 2005), MUAGCM (Melbourne University General Circulation Model; Brown et al., 2006), IsoGSM (Isotope-incorporated Global Spectral Model; Yoshimura et al., 2008), and LMDZ iso-GCM (the Laboratoire de Météorologie Dynamique atmospheric general circulation model with zooming capability; Risi et al., 2010). These models integrate the well-known fractionation physics in the model's hydrological cycle. The main objective of water isotope studies is to test the parameterization of the hydrological cycle in AGCMs with isotope data as an independent and sensitive tracer of the model's hydrology. Until recently, the isotopic distribution of water in most climate models has been compared to data from the GNIP surface network (Hoffmann et al., 1998; Noone and Simmonds , 2002; Schmidt et al., 2007; Yoshimura et al., 2008).

In recent years, several studies have been carried out to investigate the use of new data sets of water isotopes retrieved from satellite measurements. Frankenberg et al. (2009) compared the SCIAMACHY HDO measurements with the IsoGSM model. Yoshimura et al. (2011) extensively compared the HDO measurements from SCIAMACHY and TES version 4 (TES $_{\mathrm{V}}$ ) with IsoGSM results; Werner et al. (2011) compared the ECHAM5 model with SCIAMACHY; and Risi et al. (2012a) conducted an intercomparison study between models and observations, both ground-based and from satellites. Recently Frankenberg et al. (2013) compared GOSAT with LMDZ model outputs. Those studies conclude that in general the model can reproduce the geographical variability of the mean climatological delta deuterium $(\delta \mathrm{D})$ very well. However, models tend to underestimate the amplitude and the gradient of seasonal variations of $\delta \mathrm{D}$ in the midlatitudes at all atmospheric levels (Risi et al., 2012a).

When comparing satellite data with model results, the sensitivity of the satellite sensor to the different layers of the atmosphere has to be taken into account. For example, the

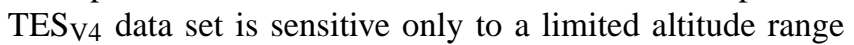
(mid-troposphere, $850-500 \mathrm{hPa}$ ), in order to reduce the impact of nonlinearities within the retrieval process (Worden et al., 2006). Therefore TES $\mathrm{V}_{4}$ is not sensitive to humidity and isotopologues in the lower troposphere. A low sensitivity means that the measured signal receives a low weight in the retrieval compared with the a priori assumed profile.

The retrieval process provides us with a quantitative measure of how much the a priori profiles have been modified by the actual satellite observations, i.e., the averaging kernel (AK). For a meaningful satellite-model comparison, the instrument operator, which is composed of the retrieval's AK and a priori constraint, must be applied to the model. The 
principle of applying the instrument operator to the model output can be formulated as $\mathrm{X}_{\mathrm{GCM}}^{\mathrm{New}}=\mathrm{X}_{\mathrm{a}}+\mathrm{A}\left[\mathrm{X}_{\mathrm{GCM}}-\mathrm{X}_{\mathrm{a}}\right]$, where $\mathrm{A}$ is the averaging kernel vector obtained from the satellite retrieval, $X_{\mathrm{a}}$ is a priori information that is used for the satellite retrieval, and $\mathrm{X}_{\mathrm{GCM}}$ is the original model field. If the satellite retrieval represents the atmospheric conditions perfectly $(\mathrm{AK}=1)$, applying the $\mathrm{AK}$ has no effect on the model results. On the other hand, if the sensitivity of the satellite retrieval is negligible, applying the AK to the model will yield the a priori profile (as does the measurement in this case).

Here, we compare the TES version 4 (V4) and 5 (V5) data sets to the ECHAM4 model output. The TES ${ }_{V 5}$ data set has greatly improved sensitivity over the V4 data set because of the use of an improved retrieval approach that depends on a larger number of HDO absorption lines, while minimizing spectral interferences from other tropospheric trace gases. Several of the studies mentioned above were carried out using the $\mathrm{TES}_{\mathrm{V} 4}$ data set. The transition between use of the TES 4 and TESV5 (Worden et al., 2012) data in the scientific studies occurred without detailed investigation of the differences and improvements between V4 and V5. Here we present the implications of the improved sensitivity of TES $\mathrm{V} 5$ data in terms of the isotope effects. For example, we show that the TES $\mathrm{V}_{5}$ data set is more sensitive to variations in the $\mathrm{HDO} / \mathrm{H}_{2} \mathrm{O}$ ratio caused by the isotope amount effect in the tropics. In addition, we evaluate how humidity biases in the models affects model-data comparisons and discuss methods to avoid these biases. The results are compared with data from SCIAMACHY, which should be less affected by the humidity bias due to its larger sensitivity near the surface.

The paper is organized as follows. In Sect. 2 we describe the SCIAMACHY, TES version 4 and 5 data sets, and the ECHAM4 model. In Sect. 3 we describe several well-known isotopic effects of water vapor. In Sect. 4 we compare the remote sensing $\delta \mathrm{D}$ data sets with the model results. In particular we discuss the consequences of applying the AK from both TES versions to the ECHAM4 model output. Conclusions are presented in Sect. 5.

\section{Instruments and methods}

\subsection{SCIAMACHY data}

The SCIAMACHY instrument aboard the European Space Agency (ESA) environmental research satellite ENVISAT measured near-shortwave infrared spectra between 2003 and 2012, which allows the retrieval of total column abundances of $\mathrm{H}_{2} \mathrm{O}$ and HDO (Frankenberg et al., 2009; Scheepmaker et al., 2013). SCIAMACHY has high sensitivity throughout the column down to the surface. The SCIAMACHY spectrometer has relatively high spectral resolution $(0.2$ to $0.5 \mathrm{~nm})$ and covers a wide wavelength range ( 240 to $1700 \mathrm{~nm}$ and 2000 to $2400 \mathrm{~nm}$ ) with an apodized spectral resolution of $0.8 \mathrm{~cm}^{-1}$, which enables SCIAMACHY to detect many different gases, clouds, and aerosols. In addition, SCIAMACHY has three different viewing geometries: nadir, limb and sun/moon occultation. HDO data were retrieved from nadir measurements using a narrow wavelength interval from 2355 to $2375 \mathrm{~nm}$ (Frankenberg et al., 2009). The footprint area of an individual HDO measurement is $120 \times 30 \mathrm{~km}$. HDO data used in this study are temporally averaged from 2003 to 2005 . Detailed information about the retrieval procedure and data processing can be found in Frankenberg et al. (2009) and Scheepmaker et al. (2013). For SCIAMACHY, the $\delta$ D total column is calculated from the retrieved $\mathrm{HDO}$ and $\mathrm{H}_{2} \mathrm{O}$ columns, in contrast to TES where the $\delta \mathrm{D}$ is very close to an optimal estimation product calculated from the spectral radiances (see below).

\subsection{TES data}

The Tropospheric Emission Spectrometer aboard the Aura satellite is an infrared Fourier transform spectrometer (FTS), which measures the spectral infrared (IR) radiances between 650 and $3050 \mathrm{~cm}^{-1}$ in the limb and a nadir-viewing mode. $\mathrm{HDO}$ and $\mathrm{H}_{2} \mathrm{O}$ abundances were obtained from TES thermal radiances between 1200 and $1350 \mathrm{~cm}^{-1}(7400$ to $8300 \mathrm{~nm}$ in wavelength) with an apodized spectral resolution of $0.1 \mathrm{~cm}^{-1}$ for the nadir view. The footprint is $5.3 \times 8.4 \mathrm{~km}$ in the nadirviewing mode. In this configuration, TES provides vertical information of abundant atmospheric species, such as $\mathrm{O}_{3}$, $\mathrm{CO}, \mathrm{CH}_{4}, \mathrm{H}_{2} \mathrm{O}$, and $\mathrm{HDO}$ (Worden et al., 2006). For the version 4 data set, weighted mean values of the isotopic composition were provided for the height interval 500 to $850 \mathrm{hPa}$, where the HDO measurements have the highest sensitivity. Detailed information about TES data in general and the TES water isotopologue data set can be found in Worden et al. (2004, 2006, 2007).

As discussed earlier, the TES retrieval version 5 has improved sensitivity near the surface and covers the altitude range from 900 to $350 \mathrm{hPa}$ (Worden et al., 2012). The increased number of radiance measurements used for retrieval and the change of both the hard constraints (e.g., retrieval levels and mapping matrices) and the soft constraints (e.g., constraint matrix) in the version 5 data set improve the TES 55 sensitivity (Worden et al., 2012). A good indicator for retrieval sensitivity is the DOF (degree of freedom), which shows how well the retrieved signal is able to capture the variability of the true distribution. There the number of data points at higher latitudes that pass the applied DOF criteria is much higher for TES $v 5$ than $\mathrm{TES}_{\mathrm{V} 4}$ (see Fig. 5 in Worden et al., 2012), clearly indicating the improvement of data quality.

For this study, we use observations from the year 2006. Filtering procedures have been applied to both versions with the same criteria, such as DOF $>0.5$ and species retrieval quality $(\mathrm{SRQ})=1$, in order to have an equal comparison. 


\subsection{The ECHAM4 model}

The ECHAM atmospheric GCM was developed at the Max Planck Institute for Meteorology in Hamburg. The ECHAM4 version used in this study was run with a spatial resolution of $2.8^{\circ}$ by $2.8^{\circ}$ (spectral resolution T42), with a vertical sigmapressure hybrid resolution of 19 layers. The ECHAM model uses a semi-Lagrangian advection scheme for both active tracers (e.g., moisture and cloud liquid water) and passive tracers (e.g., moisture and cloud water isotopologues). A detailed description of the incorporated water isotope physics can be found in Hoffmann et al. (1998). We note that the model considers fractionation effects at the surface only during evaporation from interception water and snow, however not from bare soil. Like other Iso-AGCMs, ECHAM distinguishes two types of fractionation processes: equilibrium and non-equilibrium fractionation. Equilibrium evaporation/condensation is a result of the different partial pressures of the water isotopologues, and its description in the model is straightforward. Non-equilibrium effects play a major role during evaporation from open water (i.e., the oceans), during evaporation from falling raindrops below the cloud base and during ice crystal formation in an oversaturated environment. Its parameterization within the model is based on the different molecular diffusivities.

In the ECHAM results discussed here, the model wind fields were nudged to observational data (ERA40; Uppala et al., 2005). The ECHAM data used in this study correspond to the year 2001. Details of the satellite data and the model are summarized in Table 1.

\subsection{Data processing}

\subsubsection{Unit}

All HDO data from observations and model are presented as deviation $(\delta \mathrm{D})$ from the isotopic composition of the international standard Vienna Standard Mean Ocean Water (VSMOW; Craig, 1961) expressed in per mill (\%o):

$\delta=\frac{R_{\text {sample }}}{R_{\text {VSMOW }}}-1$.

$R_{x}$ refers to the $D / H$ ratio of the sample and of the reference material, respectively. Due to the low abundance of $D$, this is very similar to the observed and modeled isotopologue ratio $\mathrm{HDO} / \mathrm{H}_{2} \mathrm{O}$, which is retrieved by the satellite and modeled in the model, and the differences between the two are negligible for our study. Positive $\delta$ values indicate an enrichment of deuterium in the sample compared to the VSMOW standard, while negative values indicate depletion of $D$.

Since the water vapor mixing ratio and $\delta \mathrm{D}$ decrease with altitude, the total column value of $\delta \mathrm{D}$ is calculated as a weighted mean:

$\overline{\delta D}=\frac{\sum_{i=0}^{n}\left(\delta D_{n} \cdot \mathrm{H}_{2} \mathrm{O}_{\mathrm{n}}\right)}{\sum_{i=0}^{n} \mathrm{H}_{2} \mathrm{O}_{\mathrm{n}}}$,

where $n$ is the number of layers. All results are given as weighted means $(\overline{\delta D})$.

\subsubsection{Application of satellite averaging kernel to model results}

In order to compare the model results to satellite observations, the ECHAM model output is convolved with the instrument operator (composed of the averaging kernel and constraint vector) from the TES satellite data sets. Unlike for real atmospheric observations, in the model the "true state" is explicitly available. By applying the AK to the model results, we mimic the way in which the satellite observes the atmosphere, to allow a meaningful comparison with the model (Rodgers, 2000; Worden et al., 2004; Bowman et al., 2006).

The monthly TES data are interpolated on the horizontal grid of the model, while in the vertical the model levels are interpolated onto the TES levels. The TES DOF and SRQ data filtering are carried out during the interpolation of all TES data into a horizontal model grid including the AK values. We do not sample the model outputs coincident with the orbital paths of the satellite since we use the monthly TES LITE data set and monthly model outputs. One should note that the AK convolution must account for the cross correlations in the joint $\mathrm{HDO}-\mathrm{H}_{2} \mathrm{O}$ profile retrieval (Yoshimura et al., 2011; Worden et al., 2006, 2011). The basic application of the AK to the model is presented in Eqs. (3) and (4). These equations can be re-formulated into Eq. (5) for the $\mathrm{HDO} / \mathrm{H}_{2} \mathrm{O}$ ratio, and to Eq. (6) for $\mathrm{H}_{2} \mathrm{O}$ (see also Supplement of Risi et al., 2013).

$$
\begin{aligned}
& \operatorname{ECHAM}_{\mathrm{AK}}=X_{\mathrm{a}}+\mathrm{A}_{\mathrm{TES}}\left[X_{\mathrm{m}}-X_{\mathrm{a}}\right] \\
& \mathrm{A}_{\mathrm{TES}}=\left[\begin{array}{ll}
\mathrm{A}_{\mathrm{DD}} & \mathrm{A}_{\mathrm{DH}} \\
\mathrm{A}_{\mathrm{HD}} & \mathrm{A}_{\mathrm{HH}}
\end{array}\right] \\
& \ln \left(\mathrm{ECHAM}_{\mathrm{AK}}^{\mathrm{R}}\right)=\ln \left(R_{\mathrm{a}}\right)+\left(\left(\mathrm{A}_{\mathrm{DD}}-\mathrm{A}_{\mathrm{HD}}\right) \cdot \ln \left(\frac{R_{\mathrm{m}}}{R_{\mathrm{a}}}\right)\right. \\
& \left.\quad+\left(\mathrm{A}_{\mathrm{DD}}-\mathrm{A}_{\mathrm{HD}}-\mathrm{A}_{\mathrm{HH}}+\mathrm{A}_{\mathrm{DH}}\right) \cdot \ln \left(\frac{q_{\mathrm{m}}}{q_{\mathrm{a}}}\right)\right) \\
& \operatorname{ECHAM}_{\mathrm{AK}}^{\mathrm{H}}=X_{\mathrm{a}}^{\mathrm{H}}+\mathrm{A}_{\mathrm{HH}}\left(X_{\mathrm{m}}^{\mathrm{H}}-X_{\mathrm{a}}^{\mathrm{H}}\right)+\mathrm{A}_{\mathrm{HD}}\left(X_{\mathrm{m}}^{\mathrm{D}}-X_{\mathrm{a}}^{\mathrm{D}}\right)
\end{aligned}
$$

$D$ and $H$ stand for $\mathrm{HDO}$ and $\mathrm{H}_{2} \mathrm{O}$, respectively, while $m$ and a stand for the model field and the a priori field, respectively. $R$ is the ratio of volume mixing ratios of $\mathrm{HDO}$ and $\mathrm{H}_{2} \mathrm{O}$ (i.e., $R_{\mathrm{a}}=\left(\mathrm{HDO} / \mathrm{H}_{2} \mathrm{O}\right)$ of TES a priori). $q$ is the specific humidity; $A_{\mathrm{DD}}$ and $A_{\mathrm{HH}}$ are the averaging kernel sub-matrices for $\mathrm{HDO}$ and $\mathrm{H}_{2} \mathrm{O} ; A_{\mathrm{HD}}$ and $A_{\mathrm{DH}}$ are the cross-correlation AK matrices between $\mathrm{H}_{2} \mathrm{O}$ and $\mathrm{HDO}$, and the vice versa (see also 
Table 1. Comparison of satellite instruments and the model used in this study.

\begin{tabular}{llll}
\hline Comparison & TES & SCIAMACHY & ECHAM \\
\hline Satellite & Aura & ENVISAT & - \\
Wavelength & $650-3050 \mathrm{~cm}^{-1}$ & $2355-2375 \mathrm{~nm}$ & - \\
Mode & Limb, nadir & Limb, nadir, sun/moon occultations & - \\
Sensitivity & $500-850 \mathrm{hPa}(\mathrm{v} 4)$ and $425-900 \mathrm{hPa}(\mathrm{v} 5)$ & total column & - \\
Resolution & $5.3 \times 8.4 \mathrm{~km}$ & $120 \times 30 \mathrm{~km}$ & $2.8^{\circ} \times 2.8^{\circ}$ \\
Layers used & $28(\mathrm{v} 4)$ and $17(\mathrm{v} 5)$ & - & 6 layers interpolated to TES layers \\
Data used & 2006 & $2003-2005$ & 2001 \\
\hline
\end{tabular}

Worden et al., 2006; Yoshimura et al., 2011; Risi et al., 2013). $\mathrm{ECHAM}_{\mathrm{AK}}^{\mathrm{R}}$ is the new $\mathrm{HDO} / \mathrm{H}_{2} \mathrm{O}$ ratio $R$ as a function of the pressure grid for the convoluted ECHAM model.

The application of the averaging kernel to the model output has two components (see Eq. 5). The first depends on the difference between the a priori $\mathrm{HDO} / \mathrm{H}_{2} \mathrm{O}$ ratio profile and the model $\mathrm{HDO} / \mathrm{H}_{2} \mathrm{O}$ ratio profile. The second depends on the difference between the a priori humidity profile and the model humidity profile. If there is a model bias in humidity, the difference between model humidity and a priori humidity will affect the model-data comparison of $\delta \mathrm{D}$. The model humidity bias commonly occurs in the upper troposphere, also in the ECHAM model. This bias may then be propagated to the lower-tropospheric $\delta \mathrm{D}$ through the averaging kernels (Worden et al., 2012; Risi et al., 2013). The effect of the model humidity bias can be eliminated by assuming that the model correctly captures the satellite a priori humidity profile. Based on this assumption, the second component, which includes the humidity term in Eq. (5), is neglected. However, this assumption also incurs an uncertainty related to the uncertainty in the a priori error in the humidity, propagated through the HDO component of the averaging kernel. In general, this error is much smaller than that due to the humidity bias and is typically less than $8 \%$ (Risi et al., 2013).

$\ln \left(\mathrm{ECHAM}_{\mathrm{AKBcorr}}^{\mathrm{R}}\right)=\ln \left(R_{\mathrm{a}}\right)+\left(\mathrm{A}_{\mathrm{DD}}-\mathrm{A}_{\mathrm{HD}}\right) \cdot \ln \left(\frac{R_{\mathrm{m}}}{R_{\mathrm{a}}}\right)$

Schneider et al. (2012) discussed the complexity of isotopologue remote sensing data sets in detail. They introduced an a posteriori method to reduce the cross dependence of retrieved $\delta \mathrm{D}$ on atmospheric humidity and to assure similar AKs for humidity and $\delta \mathrm{D}$. The ratio of water vapor isotopologues is much smaller than the variability of humidity, and the a posteriori data treatment reduces the risk of misinterpreting the remote sensing data (Schneider et al., 2012; Pommier et al., 2014; Wiegele et al., 2014). Similar AKs guarantee that the retrieved isotopologue ratio and humidity are sensitive to the same atmospheric air mass, and the cross dependence of atmospheric humidity on the retrieved $\delta \mathrm{D}$ is significantly reduced (see the appendix for details of the AK computation results). In this paper, we present results for both an a posteriori analysis of the TES version 5 data set (TESV5Pos) and the application of AK to the ECHAM model (ECHAM AK5Pos $_{\text {, }}$ following Schneider et al. (2012) and (Risi et al., 2013).

The correction of the AK by a posteriori analysis $\left(A^{\prime \prime}\right)$ is described as

$A^{\prime \prime}=C A^{\prime}$,

with $C$ and $A^{\prime}$ as follow:

$C=\left(\begin{array}{cc}A_{\mathrm{DD}}^{\prime} & \mathbb{I} \\ -A_{\mathrm{DH}}^{\prime} & \mathbb{I}\end{array}\right)$,

$A^{\prime}=P A P^{-1}$;

$P$ is described as

$P=\left(\begin{array}{cc}\frac{1}{2} \mathbb{I} & \frac{1}{2} \mathbb{I} \\ -\mathbb{I} & \mathbb{I}\end{array}\right)$.

Here, $P$ is the orthogonal basis for describing the tropospheric water vapor state: the first rows contain the $\left[\left(\ln \left[\mathrm{H}_{2} \mathrm{O}\right]+\ln [\mathrm{HDO}]\right) / 2\right]$ state, and the second rows contain the $\left[\ln [\mathrm{HDO}]-\ln \left[\mathrm{H}_{2} \mathrm{O}\right]\right]$ state. II is the identity matrix, $A$ is the averaging kernel, and $C$ is a matrix transformation for a posteriori corrected kernels. $\mathrm{ECHAM}_{\mathrm{AK} 5 \mathrm{P} \text { Pos }}$ is calculated based on Eq. (3) by replacing $A$ with $A^{\prime \prime}$, and TESV5Pos is calculated based on Eq. (20) in Schneider et al. (2012). An example for the effect of the a posteriori correction on humidity and $\delta \mathrm{D}$ AKs is shown in the Appendix.

In the case of SCIAMACHY, full AKs are not provided and thus we cannot apply the AK correction to the model. We therefore have to consider throughout this work that some effects of the cross dependency between $\mathrm{H}_{2} \mathrm{O}$ and $\delta \mathrm{D}$, and differences in the sensitivity of $\mathrm{H}_{2} \mathrm{O}$ and $\delta \mathrm{D}$, might affect the interpretation of the SCIAMACHY data.

\subsubsection{Bias correction}

A bias of $\sim 5 \%$ on average and $\sim 15 \%$ maximum, evaluated from ground and aircraft measurements, in the TES HDO vapor data has been attributed to uncertainties in the spectroscopic line strengths (Worden et al., 2006, 2007, 2011; Herman et al., 2014). A correction for this bias is already included in the version 5 data set (Worden et al., 2012) but 
not in version 4 . The sensitivity of the measurements must be accounted for in the application of the bias correction to the

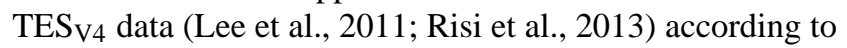

$X_{\text {corrected }}^{\mathrm{HDO}}=X_{\text {original }}^{\mathrm{HDO}}-\mathrm{A}_{\mathrm{DD}}\left(\delta_{\text {bias }}\right)$.

$X_{\text {corrected }}^{\mathrm{HDO}}$ is the logarithm of the volume mixing ratio of the HDO profile after bias correction, $X_{\text {original }}^{\mathrm{HDO}}$ is the logarithm of the original volume mixing ratio of the model or satellite, and $\delta_{\text {bias }}$ is a column vector of the same length as $X_{\text {original }}^{\mathrm{HDO}}$ that contains the bias correction values. Note that this correction is only applied to $\mathrm{HDO}$ and not to $\mathrm{H}_{2} \mathrm{O}$. We applied the bias corrections of $5 \%$ to $\mathrm{TES}_{\mathrm{V} 4}$ (Worden et al., 2006; Herman et al., 2014), and no bias correction was applied to TESV5 since it has already been corrected by $6.5 \%$ (Worden et al., 2012). To improve the agreement amongst the data set in the tropics, bias corrections of $3 \%$ and $5 \%$ were applied to $\mathrm{ECHAM}_{\mathrm{AK} 4}$ and SCIAMACHY, respectively.

\section{The isotope effects}

Before presenting the results of our study, we briefly summarize the most important spatial and temporal isotope features and their underlying mechanisms. We focus in the following on $\delta \mathrm{D}$; similar arguments hold for $\delta^{18} \mathrm{O}$.

Since the start of water isotopologue studies in the 1960 s (Dansgaard, 1964) a number of empirical relationships between the isotopic composition of precipitation and several geographical or climatological parameters have been established. The principal "isotopic effects" - such as the temperature effect, the amount effect, the altitude effect, and the latitudinal effect - will be used in the following to make a first-order evaluation of the satellite data and the model results. The temperature effect denotes the spatial relationship between annual (or monthly or seasonal) mean temperatures and $\delta \mathrm{D}$ of the respective precipitation (i.e., annual or monthly or seasonal mean). A linear relationship holds over a wide temperature range. The altitude effect and the latitudinal effect denote linear relationships between $\delta \mathrm{D}$ and these geographical quantities. Since both quantities, i.e., altitude and latitude, correlate strongly with temperature, both effects are partly a direct consequence of the spatial temperature effect. However, there are some mechanisms involved that are independent of temperature. For instance, the triggering of strong convective activity next to orographic obstacles contributes to the altitude effect.

In the tropics (latitudes $< \pm 15^{\circ}$ ), the linear relation between surface temperatures and $\delta \mathrm{D}$ becomes less apparent. More frequent convectively formed precipitation and thus more vertical air movement seem to disturb the control of the temperature effect. However, in particular in tropical and subtropical regions, a relation between the amount of precipitation and $\delta \mathrm{D}$ (the amount effect) appears in the data, for which a full explanation is still under debate (Dansgaard,
1964; Aggarwal et al., 2007; Risi et al., 2008). Another geographical isotope effect is the continental effect. Along the trajectory across large continental land masses, air is disconnected from the oceanic water supply to compensate for the successive rain events. This leads again to a distillation effect, with the heavier isotopes being progressively removed from these traveling air masses. The continental effect is therefore also related to the temperature effect but adds an additional mechanism to the purely temperature-controlled rainout processes. It is particularly pronounced along principal air mass trajectories, e.g., from the Gulf of Mexico into the southwest of the United States or from the North Atlantic into western and central Europe.

We show below that the isotope effects mentioned above are clearly represented in the TES ${ }_{\mathrm{V} 5}$ data set and to a lesser degree in the $\mathrm{TES}_{\mathrm{V} 4}$ data set. In addition, the isotope amount effect associated with the movements of Intertropical Convergence Zone (ITCZ) is clearly shown in TES $\mathrm{V}_{5}$. This is an important effect of lower-tropospheric water isotopologues that has not been well documented in previous studies. In chapter 4 we will discuss more systematically these isotope effects in all data sets and describe the improvement of the isotope effects in the TES $\mathrm{V} 5$ data set compared to V4.

\section{Results and discussion}

\subsection{Spatial isotope distribution}

The annual mean $\delta \mathrm{D}$ isotope distributions of the different satellite and model data sets and the satelitte's a priori are shown in Figs. 1 and 2. The TES and SCIAMACHY prior profiles that are used as an initial guess for $\mathrm{HDO}$ and $\mathrm{H}_{2} \mathrm{O}$ to constrain the $\mathrm{HDO} / \mathrm{H}_{2} \mathrm{O}$ estimation do not show a latitudinal effect (Fig. 1a and b). The TES prior for HDO $\left(\mathrm{HDO}_{\text {prior }}\right)$ was calculated based on atmospheric $\mathrm{H}_{2} \mathrm{O}$ profiles from reanalysis data, multiplied by a single a priori profile of the $\mathrm{HDO} / \mathrm{H}_{2} \mathrm{O}$ ratio, which was obtained from a run of the National Center for Atmospheric Research (NCAR) Community Atmosphere Model (CAM), augmented with an isotope physics approach developed by Noone and Simmonds (2002), Worden et al. (2006, 2012), and Zhang et al. (2010). This prior HDO profile is representative for the tropical $\mathrm{HDO} / \mathrm{H}_{2} \mathrm{O}$ ratio, and as a result the TES $\delta \mathrm{D}$ prior is strongly biased high at high latitudes. The TES prior does include an altitude effect (Fig. 1a), which is clearly visible in the Himalayas, the Andes, the Rocky Mountains, and Greenland. The prior for TES version 5 is not significantly different from version 4.

The SCIAMACHY prior shows a similar pattern to the TES prior (Fig. 1b) but generally lower $\delta \mathrm{D}$ values of -140 to $-160 \%$ o. It does not include a latitudinal gradient and altitude effect. The sensitivity to the weak HDO absorber is close to unity throughout the column (Frankenberg et al., 2009; Scheepmaker et al., 2013), so it is sensitive to 


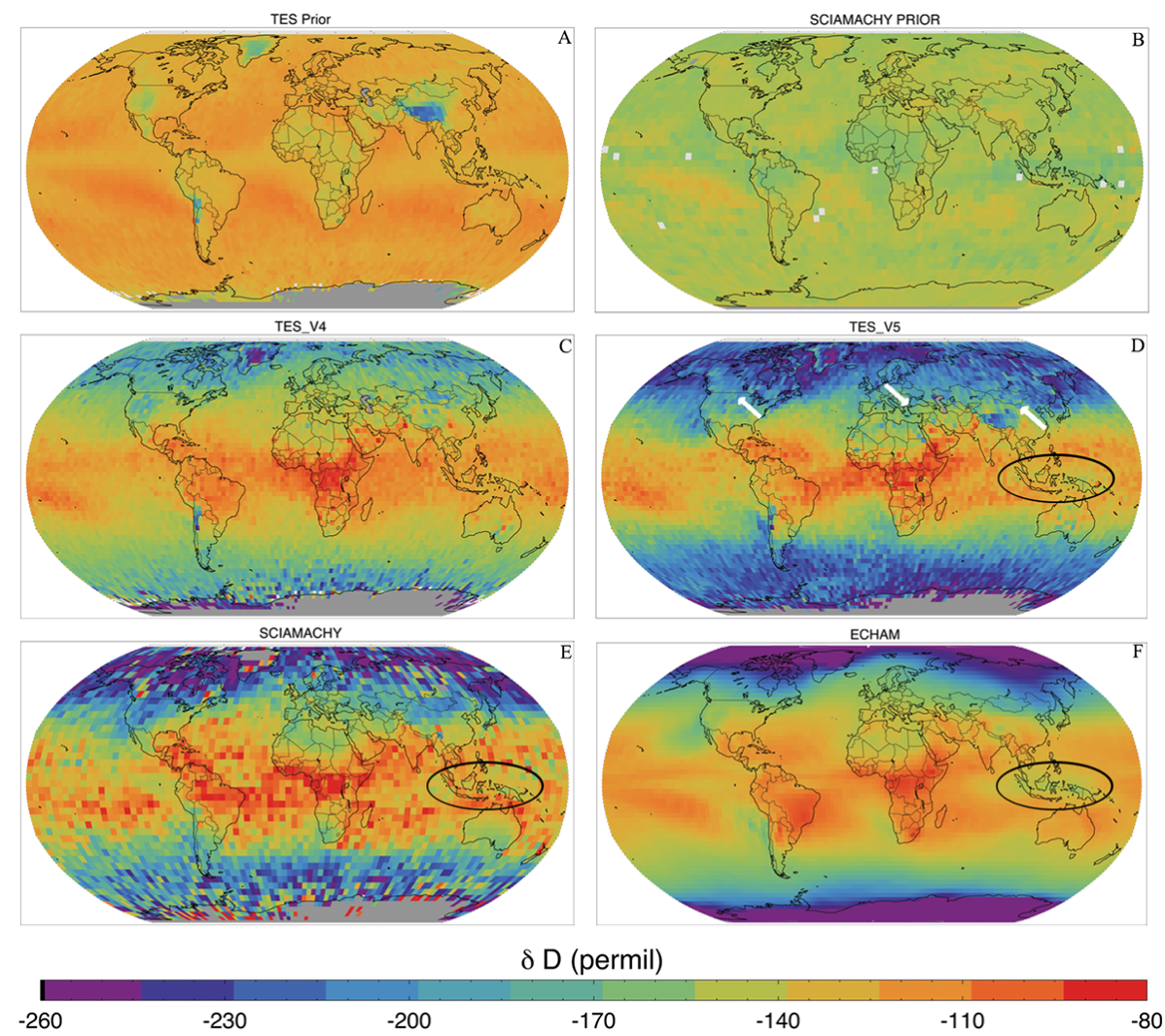

Figure 1. TES prior version 4 (a), SCIAMACHY prior (b), $\delta \mathrm{D}$ product from TES 4 (c), TES 55 (d), SCIAMACHY (e), ECHAM (f). The figures of TES prior and TES 4 are weighted averaged between 850 and $500 \mathrm{hPa}$, and TESV5 and ECHAM between 900 and $425 \mathrm{hPa}$. The results are bias-corrected by 5 and $-5 \%$ for TES 44 and SCIAMACHY, respectively. Arrows in (d) point out the continental effect, and ellipses in (d), (e), and (f) show the region with a strong isotope amount effect around Indonesia. All plots are annual average $\delta \mathrm{D}$.

near-surface water vapor. The SCIAMACHY prior was constructed from ECMWF water vapor profiles and a fixed prior depletion profile that decreases from $-100 \%$ at the lowest layer to $-500 \%$ at the highest layer. This results in the prior $\mathrm{H}_{2} \mathrm{O}$-weighted total column $\delta \mathrm{D}$ value of approximately $-150 \%$.

Figures $1 \mathrm{c}$ to $\mathrm{f}$ and $2 \mathrm{a}$ to e present modeled and observed patterns (isoscapes) of total column $\delta \mathrm{D}$ of atmospheric water vapor. The first-order isotope feature shown in all figures is the significant difference in $\delta \mathrm{D}$ between low, mid, and high latitudes roughly following global temperatures. The latitude effect is stronger in the observed global isotope pattern of the TES version 5 (TES $_{\mathrm{V} 5}$ ) and of the SCIAMACHY data set than in the TES version 4 (TES $\left.{ }_{V 4}\right)$. It is also present in the modeled results of ECHAM. ECHAM results convolved with the instrument operator of TES version $4\left(\mathrm{ECHAM}_{\mathrm{AK} 4}\right)$ shows a smaller latitude gradient than for version $5\left(\mathrm{ECHAM}_{\mathrm{AK} 5}\right)$. Another feature, visible in these global isoscapes, is that the tropical and subtropical zones with enriched values are wider in the ECHAM model results (Figs. 1f, 2a-d) compared to the TES $\mathrm{V}_{5}$ and SCIAMACHY satellite observations (Fig. 1d and e).
A strong latitude effect on the order of $\sim 150 \%$ o for $\delta \mathrm{D}$ between the tropics and the cold and isotopically depleted polar regions of both hemispheres is well established in the literature. Isoscapes based on an interpolated multi-variable regression of GNIP precipitation data also show such strong latitudinal gradients (Bowen and Wilkinson, 2002). Also the few existing near-surface vapor measurements (Uemura et al., 2008) indicate a strong isotopic gradient between low and high latitudes. This principal geographical pattern is better represented in $\mathrm{TES}_{\mathrm{V} 5}$ compared to TES $\mathrm{V}$, which has a stronger influence from the a priori field at higher latitudes. It clearly indicates a substantial improvement of the version 5 retrieval over version 4 .

The altitude effect is apparent in all data sets. Major mountain chains such as the Andes, Rocky Mountains, or the Himalayas together with the Tibetan Plateau are easily recognizable by lower $\delta \mathrm{D}$ values. $\mathrm{ECHAM}_{\mathrm{AK} 5}$, however, shows unrealistically high $\delta \mathrm{D}$ values over the Tibetan Plateau (Himalayas; Fig. 2b). This unrealistic pattern is due to a high bias in the model humidity profile as discussed in Sect. 2.4 (Risi et al., 2012b, 2013) and the effect of limited vertical resolution and a priori constraints on retrieved $\delta \mathrm{D}$ over the Himalaya region. Therefore, this problem disappears when 
we leave out the humidity term in the application of the instrument operator (Eq. 7), and the resulting ECHAM $_{\mathrm{AK} 5 \mathrm{BC} \text { Corr }}$ shows a local isotope minimum over the Tibetan Plateau again (Fig. 2d). Thus, the humidity bias can have a large effect on the isotope results of a model convolved with the averaging kernel of a satellite instrument.

The unrealistically high $\delta \mathrm{D}$ values over the Tibetan Plateau also disappear if we perform the a posteriori analysis suggested by Schneider et al. (2012) and Pommier et al. (2014) (Fig. 2c). The a posteriori data treatment results in $\delta \mathrm{D}$ and $\mathrm{H}_{2} \mathrm{O}$ profiles that are sensitive to the same atmospheric air mass. The AK application to the model with applied a posteriori analysis produces a similar result to the humidity correction (Fig. 2c and d). Latitudinal profiles from both ECHAM $_{\mathrm{AK} 5 \text { Corr }}$ and ECHAM $\mathrm{AK}_{\mathrm{APOs}}$ show very similar $\delta \mathrm{D}$ values in the tropics and only $2-5 \%$ differences at the higher latitudes (Fig. 3c). Both correction procedures thus show that humidity biases have to be taken into account when the satellite AKs are applied to model results, either by a humidity correction or an a posteriori processing.

The isotopically most enriched water vapor is found over tropical South America and tropical Africa, and is associated with the Amazon and Congo River basins. The intense recycling and very strong evapotranspiration over these rainforest regions, in combination with shallow convection, are responsible for this pattern (Worden et al., 2007; Yoshimura et al., 2011). The location and extension of these isotope maxima are relatively robust throughout all data sets. Since these large areas with $\delta \mathrm{D}$ between -110 and $-100 \%$ are not apparent in the TES and SCIAMACHY a priori fields (Fig. 1a and b) but clearly appear in the final products (Fig. 1c, d, and e), they are a robust result of the added information from the satellite measurements and not an artificial product of the retrieval procedure. This result is consistent with the previous studies from Yoshimura et al. (2011), Werner et al. (2011), and Risi et al. (2012a), which yield $\delta \mathrm{D}$ values between -80 and $-110 \%$. A study from Brown et al. (2008), however, shows that lower $\delta \mathrm{D}$ values of -150 to $-165 \%$ are also observed in these regions, but these lower values are related to seasonal tropical convection and the corresponding amount effect.

In the scientific literature, many examples of the continental effect are documented, e.g., the southwestern US or western/central Europe, based on measurements in groundwater (Rozanski, 1985) and precipitation (Aggarwal et al., 2007). The continental effect appears in all data sets with varying intensity, except for ECHAM convoluted with AK version 4. TES ${ }_{\mathrm{V} 4}$, TES ${ }_{\mathrm{V} 5}$, TES V5Pos, SCIAMACHY, ECHAM,

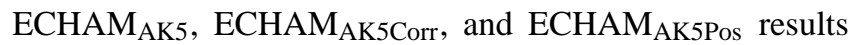
clearly show the continental effect (white arrows in Figs. 1d and 2d.).

The Hadley-Walker circulation defines the seasonally varying zones of strong convective activity in the tropics. Three rising branches of the meridional Walker circulation are situated over tropical South America, tropical Africa, and the western Pacific warm pool (Oort and Yienger, 1996). As described above, the strong isotope enrichment over the continental parts of the Walker circulation is due to the intense recycling of continental water. These yearly averages are in balance, weighted towards these enriching effects as opposed to depleting effects associated with seasonal convection that are also observed by TES (Brown et al., 2008; Samuels-Crow et al., 2014). However, over the Pacific warm pool one recognizes a zone with slightly lower $\delta \mathrm{D}$ (ellipses in Figs. 1d$\mathrm{f}$ and $2 \mathrm{c}-\mathrm{e}$ ). This area of very high sea surface temperature (SST), persistent strong convection and rainfall, and more depleted vapor extends over the inner tropics and is surrounded by a zone of descending air, less rainfall (Oort and Yienger, 1996; Jo et al., 2014), and more enriched vapor. We consider this pattern as a manifestation of the isotopic amount effect since the isotopic pattern anti-correlates with regional rainfall (Brown et al., 2008; Dansgaard, 1964; Kurita et al., 2011; Lee and Fung , 2007; Lee et al., 2011; Risi et al., 2008; Worden et al., 2007). Apparently, TES $\mathrm{V}_{4}$ and ECHAM $_{\mathrm{AK} 4}$ (Figs. 1c and 2a) do not pick up this important feature of the tropical water cycle. TES $\mathrm{V}_{5}$ clearly shows the depletion of water vapor over this region, with a $\delta \mathrm{D}$ value difference of $\sim 22 \%$ o compared to V4.

Figure 3 presents a comparison of zonal mean $\delta \mathrm{D}$ values for all data sets. As discussed above, $\delta \mathrm{D}$ decreases to $-200 \%$ in the $\mathrm{TES}_{\mathrm{V} 4}$ product at high northern latitudes, whereas it decreases to $-250 \%$ o for $\mathrm{TES}_{\mathrm{V} 5}$, the latter in agreement with SCIAMACHY, and with other independent observations (Uemura et al., 2008). The differences between ECHAM4 and SCIAMACHY in our study are consistent with results from Werner et al. (2011) for ECHAM5 and SCIAMACHY. The difference between ECHAM5 and SCIAMACHY is $\sim 20 \%$ in the tropics and $\sim 25 \%$ at the higher latitudes $\left(60^{\circ} \mathrm{N}-\mathrm{S}\right.$; Werner et al., 2011). Here, the differences between ECHAM4 and SCIAMACHY amount to between 10 and $20 \%$ in the tropics and at the higher latitudes $\left(60^{\circ} \mathrm{N}-\mathrm{S}\right)$. TES $\mathrm{V}_{4}$ displays much weaker $\delta \mathrm{D}$ gradients at midlatitudes compared to SCIAMACHY and TESV5. As mentioned earlier, the tropical and subtropical isotope maximum in the ECHAM model is significantly wider than for SCIAMACHY and TESV5 (Fig. 3b). This issue is aggravated when the ECHAM results are convolved with the TES averaging kernels. The ECHAM $\mathrm{AK}_{4}$ product shows the smallest latitude gradient and highest $\delta \mathrm{D}$ values at high latitude of all data sets. The small AK values of version 4 enhance the influence of the a priori field, which consequently leads to larger $\delta \mathrm{D}$ values. This high-latitude problem has been improved in the version 5 data sets (Fig. 3b), but still the $\mathrm{ECHAM}_{\mathrm{AK} 5}, \mathrm{ECHAM}_{\mathrm{AK} 5 \mathrm{Corr}}$, and $\mathrm{ECHAM}_{\mathrm{AK} 5 \mathrm{Pos}}$ results are significantly higher than the model state of ECHAM at northern high latitudes (Fig. 3c). TES 5 and TES 5 Pos are in good agreement with SCIAMACHY.

We note that the different climatological periods that are used in the comparison between TES (2006), ECHAM4 (2001), and SCIAMACHY (2003-2005) can also contribute 


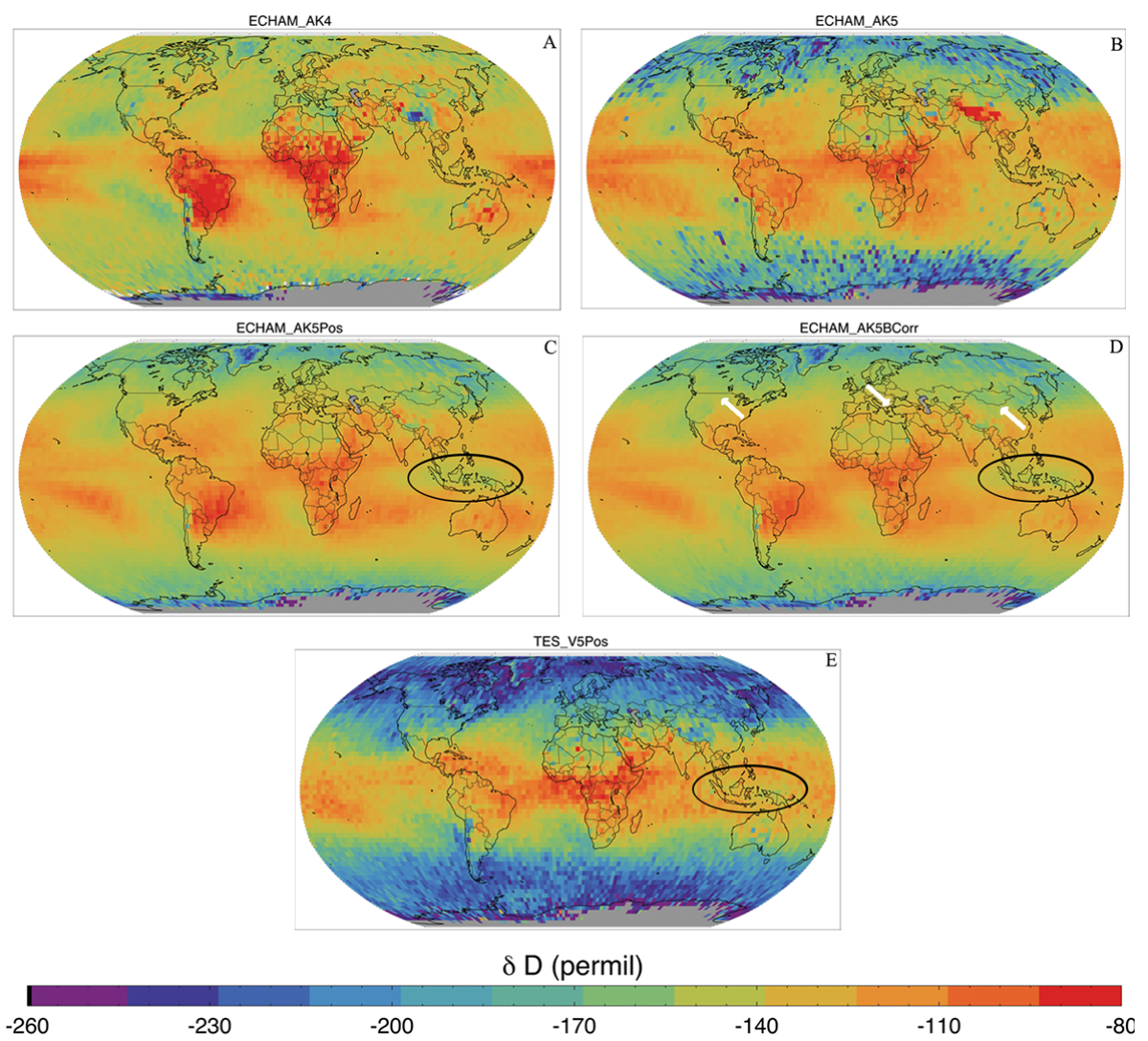

Figure 2. $\delta$ D product from $\mathrm{ECHAM}_{\mathrm{AK} 4}(\mathbf{a}), \mathrm{ECHAM}_{\mathrm{AK} 5}(\mathbf{b}), \mathrm{ECHAM}_{\mathrm{AK} 5 \mathrm{Pos}}$ (c), $\mathrm{ECHAM}_{\mathrm{AK} 5 \mathrm{Corr}}$ (d), and TES $\mathrm{V}_{\mathrm{VPos}}$ plot (e). All figures are weighted averaged between 900 and $425 \mathrm{hPa}$. The $\mathrm{ECHAM}_{\mathrm{AK} 4}$ result is bias-corrected by $3 \%$. Arrows in (d) point out the continental effect, and ellipses in (c), (d), and (e) show the region with a strong isotope amount effect around Indonesia. All plots are annual average $\delta \mathrm{D}$.

to the difference between these data sets, although the general latitudinal distribution is not expected to show strong interannual variations.

Although there are significant discrepancies at mid- and high latitudes, all data products agree fairly well in a tropical/subtropical band between $30^{\circ} \mathrm{N}$ and $30^{\circ} \mathrm{S}$ with values around $-100 \%$, similar to the results of Webster and Heymsfield (2003), Lawrence et al. (2004), and Zakharov et al. (2004). It seems therefore that different remote sensing data sets and model results (with AK applied) coincide in the tropics, which means that the isotope measurements there can be exploited to examine smaller-scale effects (see below).

\subsection{Seasonal isotope distribution}

Above we analyzed the spatial structure of the dominant annual average isotope patterns. In addition, both satellite data and model simulations allow us to study the seasonality of $\delta \mathrm{D}$ patterns and to identify the leading processes on this timescale. Zonal means of all data sets are computed for the mean winter (DJF) and summer season (JJA) of the respective annual time period (Fig. 4). TES $\mathrm{V} 5$ shows similar results as SCIAMACHY during summer and winter in the Northern Hemisphere (NH), and both data sets show a clear and consistent seasonal isotope difference between the two seasons in the Northern Hemisphere. In the Southern Hemisphere, however, the difference between the two seasons is much smaller for both data sets. In addition, in the Southern Hemisphere there appears to be a significant difference between the instruments. TES ${ }_{\mathrm{V} 5} \delta \mathrm{D}$ values are consistently lower compared to SCIAMACHY (Fig. 4a). It is unlikely that the different simulation and observation periods in our analysis can explain these large discrepancies.

Due to the high solar zenith angle (low sun), SCIAMACHY data are seasonally scarce at mid- and high latitudes. Therefore, there are not many measurements above $50^{\circ} \mathrm{N}$ or $50^{\circ} \mathrm{S}$ in the respective winter season (Fig. 4a). Also, large parts of the oceans are not covered due to the low albedo of the ocean, and the signals from oceanic regions are primarily above low-level clouds. For our analysis we use the same data filtering procedure of SCIAMACHY data as in Frankenberg et al. (2009), which only accepts water isotopologue measurements if the $\mathrm{H}_{2} \mathrm{O}$ total column corresponds to at least $70 \%$ of the ECMWF total water column. This constraint excludes profiles with high clouds but accepts profiles 

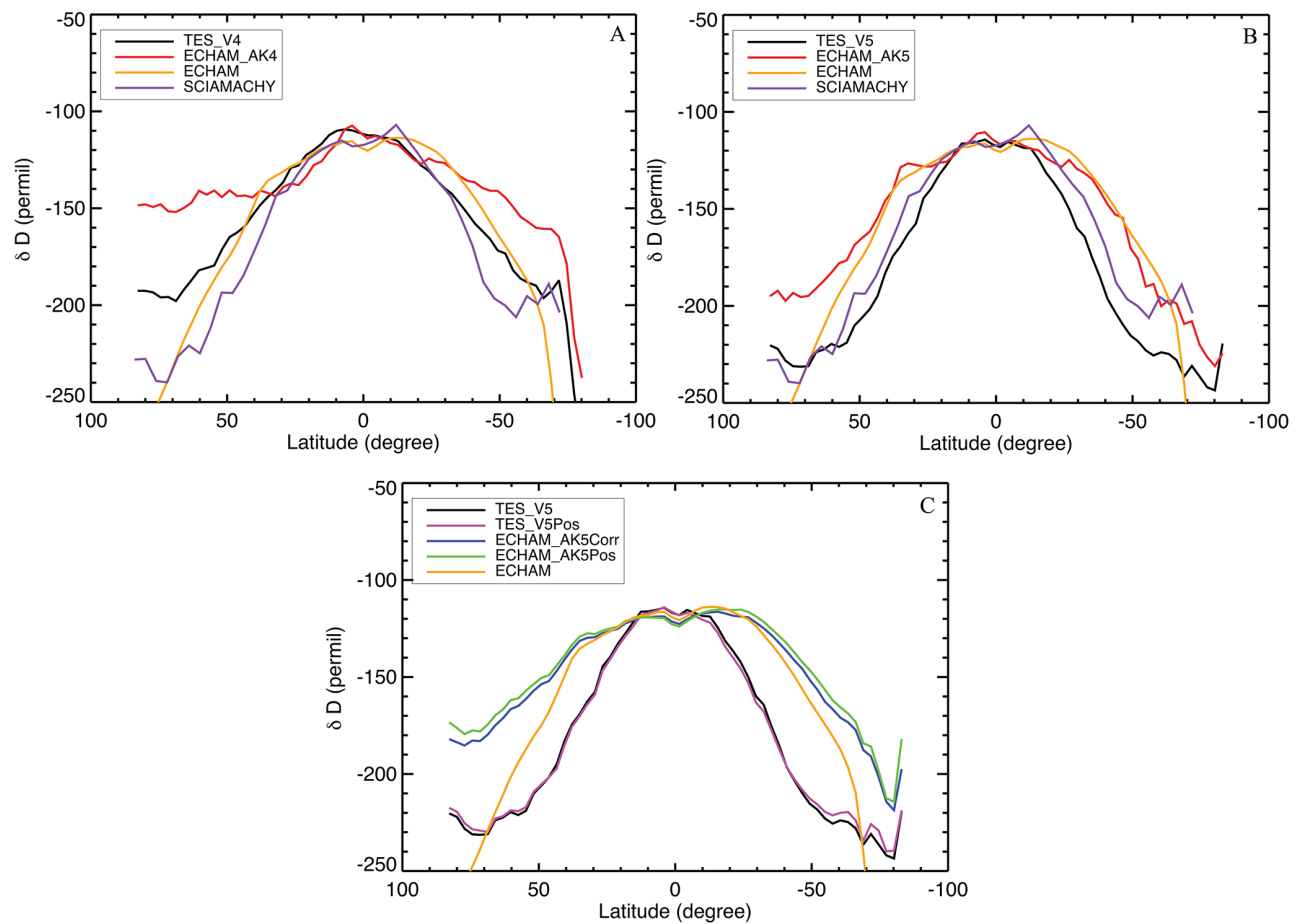

Figure 3. Annual average latitude profile of $\delta \mathrm{D}$ in water vapor from TES, TES $\mathrm{V5Pos}, \mathrm{ECHAM}_{\mathrm{B}} \mathrm{ECHAM}_{\mathrm{AK}}, \mathrm{ECHAM}_{\mathrm{AK} 5 \mathrm{Corr}}$,

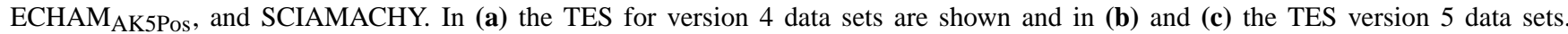
(a) is weighted averaged between 850 and $500 \mathrm{hPa}$, and (b) and (c) are weighted averaged between 900 and $425 \mathrm{hPa}$.
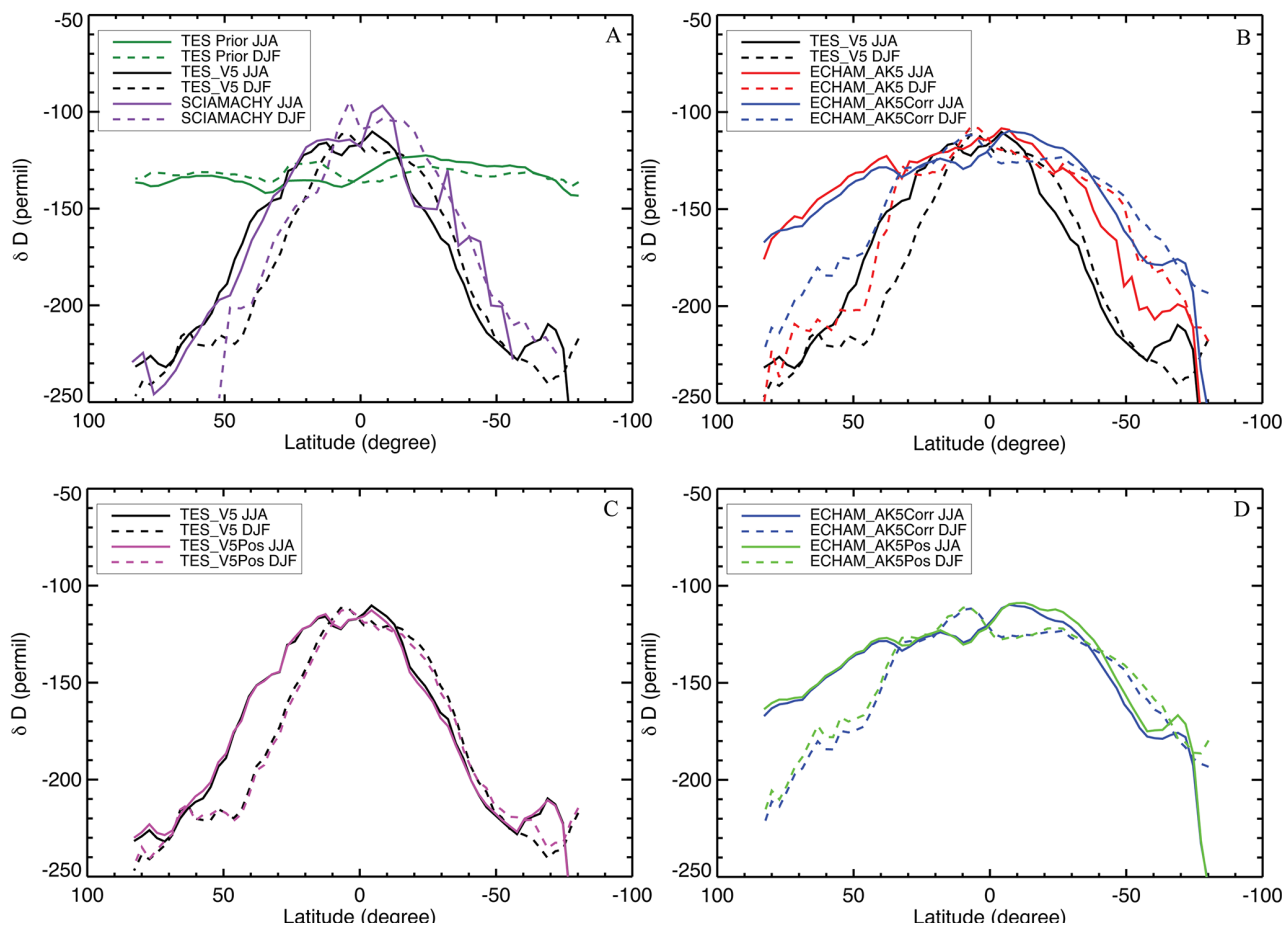

Figure 4. Seasonal comparison of zonal means of $\delta \mathrm{D}$ from TES prior, TES $\mathrm{V}_{\mathrm{5}}$, and SCIAMACHY (a); from TES $\mathrm{V}_{\mathrm{V}}$, ECHAM $\mathrm{EK}_{\mathrm{A} 5}$, and

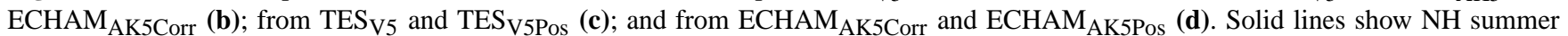
profiles and dashed lines NH winter profiles. All figures are weighted averaged between 900 and $425 \mathrm{hPa}$. 
with low clouds (up to $1 \mathrm{~km}$ ). Thus all SCIAMACHY measurements are biased towards clear-sky or low-cloud conditions. The $\delta$ D seasonality of SCIAMACHY shown in Fig. 4a (especially in the Southern Hemisphere during the Northern Hemisphere summer) is therefore neither temporally nor spatially fully representative of the mean state of the atmosphere. These issues are not applicable to TES data. However, TES measurements are also less sensitive at higher latitudes, especially the version 4 data set.

The wider tropical maximum of ECHAM is seen in both seasons (Fig. 4b and d). It is apparent that in the summer season the $\mathrm{ECHAM}_{\mathrm{AK} 5}$ results show considerably higher $\delta \mathrm{D}$ values than TES ${ }_{V 5}$ in the Northern Hemisphere and vice versa for the winter season in the Southern Hemisphere. This shows that the annual bias in ECHAM, as discussed above, originates to a large degree from the summer season. The midlatitude bias found in the ECHAM model is a common bias that is present in many GCMs. In general, most GCMs tend to overestimate humidity in the tropics and subtropics due to inadequate representation of cloud processes or of the large-scale circulation, or to excessive diffusion during the transport of water vapor (Risi et al., 2012a, b). The overestimation of humidity in the subtropics affects the enrichment of $\delta \mathrm{D}$ in the mid- and high troposphere.

Whereas there are still some discrepancies between the different data products at mid- and high latitudes, isotope data within a zonal band from 30 to $-30^{\circ} \mathrm{N}$ are roughly consistent, both for the annual average and the summer and winter profiles. An interesting feature of all data sets except for $\mathrm{TES}_{\mathrm{V} 4}$ (not shown) is a seasonal seesaw behavior of the latitudinal $\delta \mathrm{D}$ profiles in the inner tropics: in both seasons, the $\delta \mathrm{D}$ values close to the Equator are lower in the respective summer hemisphere than in the winter hemisphere. The absolute $\delta \mathrm{D}$ variations are small and extend over different ranges in the respective hemispheres, but the $\delta \mathrm{D}$ latitude profiles for the two seasons (solid and dashed lines of each color) intersect very close to the Equator.

This seasonal variation of $\delta \mathrm{D}$ in the tropics is a robust feature of the TES $v 5$ data set and a consequence of the seasonal displacements of the ITCZ rainfall bands and corresponding convective activity, which closely follow the maxima of insolation. The ITCZ is displaced towards the north during Northern Hemisphere summer and towards the south during Southern Hemisphere summer. Due to the isotopic amount effect, we expect the convectively active regions within the ITCZ to be associated with lower $\delta \mathrm{D}$ values. Therefore, areas north (south) of the Equator are isotopically more (less) depleted during $\mathrm{NH}$ summer, and vice versa during $\mathrm{NH}$ winter. The isotopic amount effect therefore leads to the seesaw behavior of the zonal $\delta \mathrm{D}$ means where the latitudinal profiles in the two seasons have their lower values in the summer hemisphere (see the crossing lines in Fig. 5). This seesaw behavior has already been recognized in precipitation data (Waliser and Gautier , 2010; Wu et al., 2003; Back and Bretherton , 2005).
SCIAMACHY and TES $\mathrm{V}_{5}$ show this isotope feature with varying intensity (Fig. 5a). The amount effect due to the movement of ICTZ is more pronounced in SCIAMACHY than in TES ${ }_{V 5}$. The original ECHAM model,

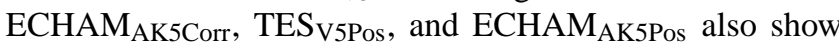
this seesaw pattern (Fig. 5b and c). The seesaw pattern seen in TES $v 5$ Pos indicates that the cross dependency of $\mathrm{H}_{2} \mathrm{O}$ on $\delta \mathrm{D}$ has no influence in this seesaw behavior.

A possible reason why SCIAMACHY shows this seesaw pattern more clearly is SCIAMACHY's higher sensitivity at lower altitudes where many processes contributing to the amount effect occur (such as re-evaporation of raindrops in more/less humid air, etc). In order to investigate this further,

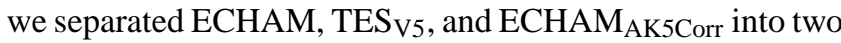
layers (Fig. 6). Figure 6b confirms that the seesaw pattern in the TES $\mathrm{V}_{5}$ originates from the lower layer. This is qualitatively in line with the fact that SCIAMACHY is sensitive down to the surface and the seesaw pattern nicely shows up in the SCIAMACHY data set. We note that this was not necessarily expected since the seesaw phenomenon is largely produced by displacements of the ITCZ over the oceans, where the SCIAMACHY coverage is relatively low (due to the requirement of low-level clouds) compared to the coverage over land. In contrast, ECHAM and $\mathrm{ECHAM}_{\mathrm{AK} 5 \mathrm{Corr}}$ show the seesaw pattern throughout the entire atmospheric column, both at the lower and high layers (Fig. 6a and c). It seems that the model overestimates the correlation between lower and higher layers compared to the observations. It was speculated that GCMs in general show strong coherence between processes at lower altitudes (such as sea surface temperature variations) and associated features at high altitudes (such as high convective cloud formation). In this case the common isotope seasonality at low and high altitudes in the model might be a further consequence of these known model problems (Risi et al., 2012a; Conroy et al., 2013).

The representation of this "fine structure" in the tropics is an important feature, which needs further investigation in remote sensing data sets of water isotopologues. It should be noted that the cloud height issue might contribute to or even cause the seesaw pattern seen in the satellite data sets. Satellites in general measure above thick clouds but can measure through optically thin clouds (e.g., Lee et al., 2011). Thus, above convection, the satellite data are representative for $\delta \mathrm{D}$ at higher altitudes where $\delta \mathrm{D}$ is lower.

\subsection{Relation of water vapor and $\delta \mathrm{D}$}

Already in 1964, Dansgaard (1964) described the water isotopologues within the global water cycle by means of a Rayleigh-type distillation model. Each condensation process extracts a certain quantity of water from an air mass and fractionates the water isotopologues according to the respective temperature. This successive extraction of the heavier isotopologues by distillation happens both during transport from the tropical/subtropical source regions to higher lati- 

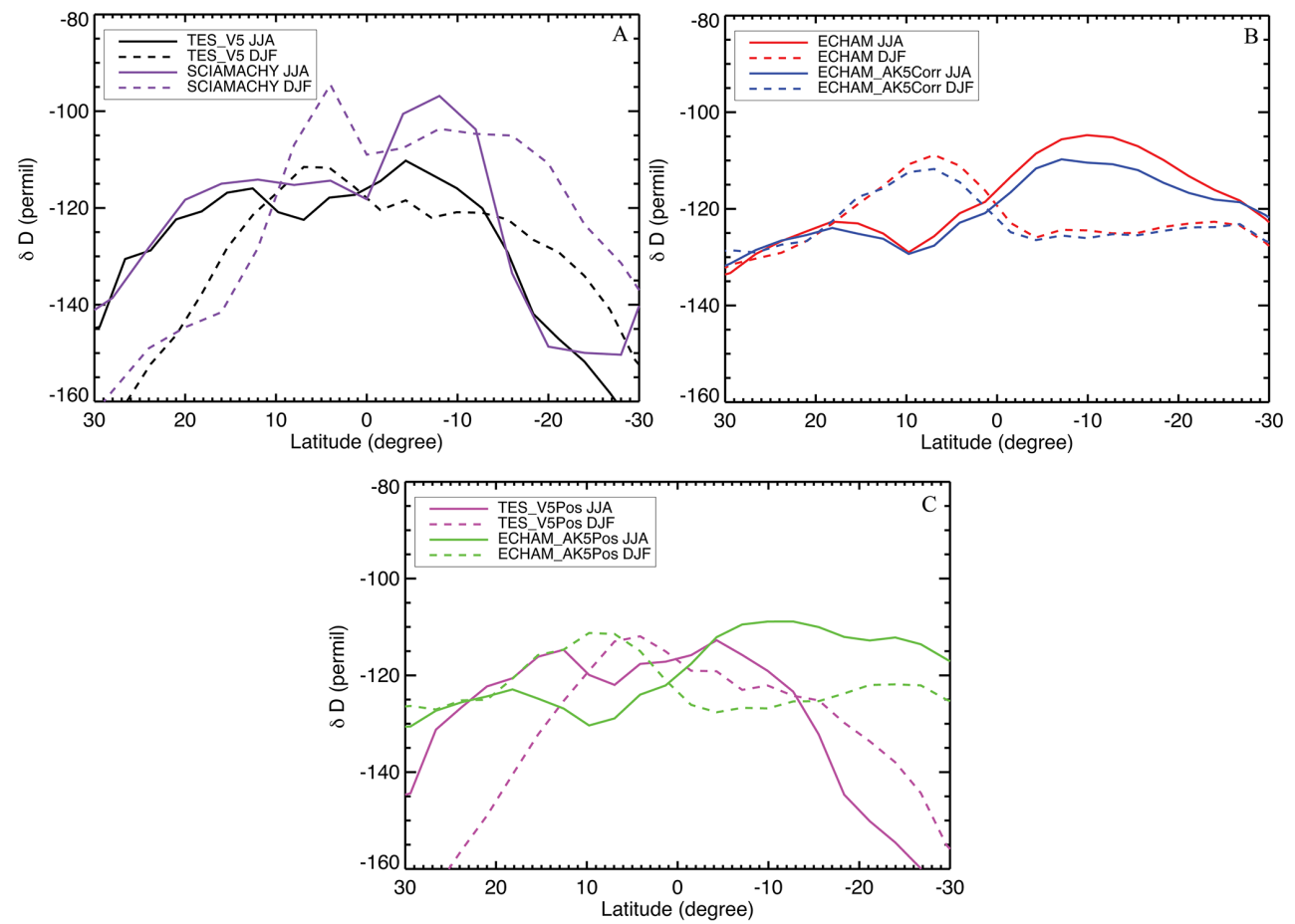

Figure 5. Latitudinal $\delta \mathrm{D}$ profiles between $30^{\circ} \mathrm{N}$ and $30^{\circ} \mathrm{S}$ in northern summer (JJA, solid lines) and northern winter (DJF, dashed lines) of

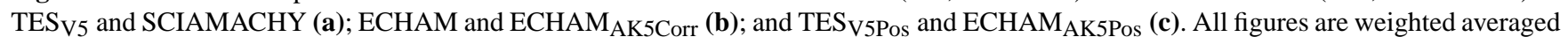
between 900 and $425 \mathrm{hPa}$.
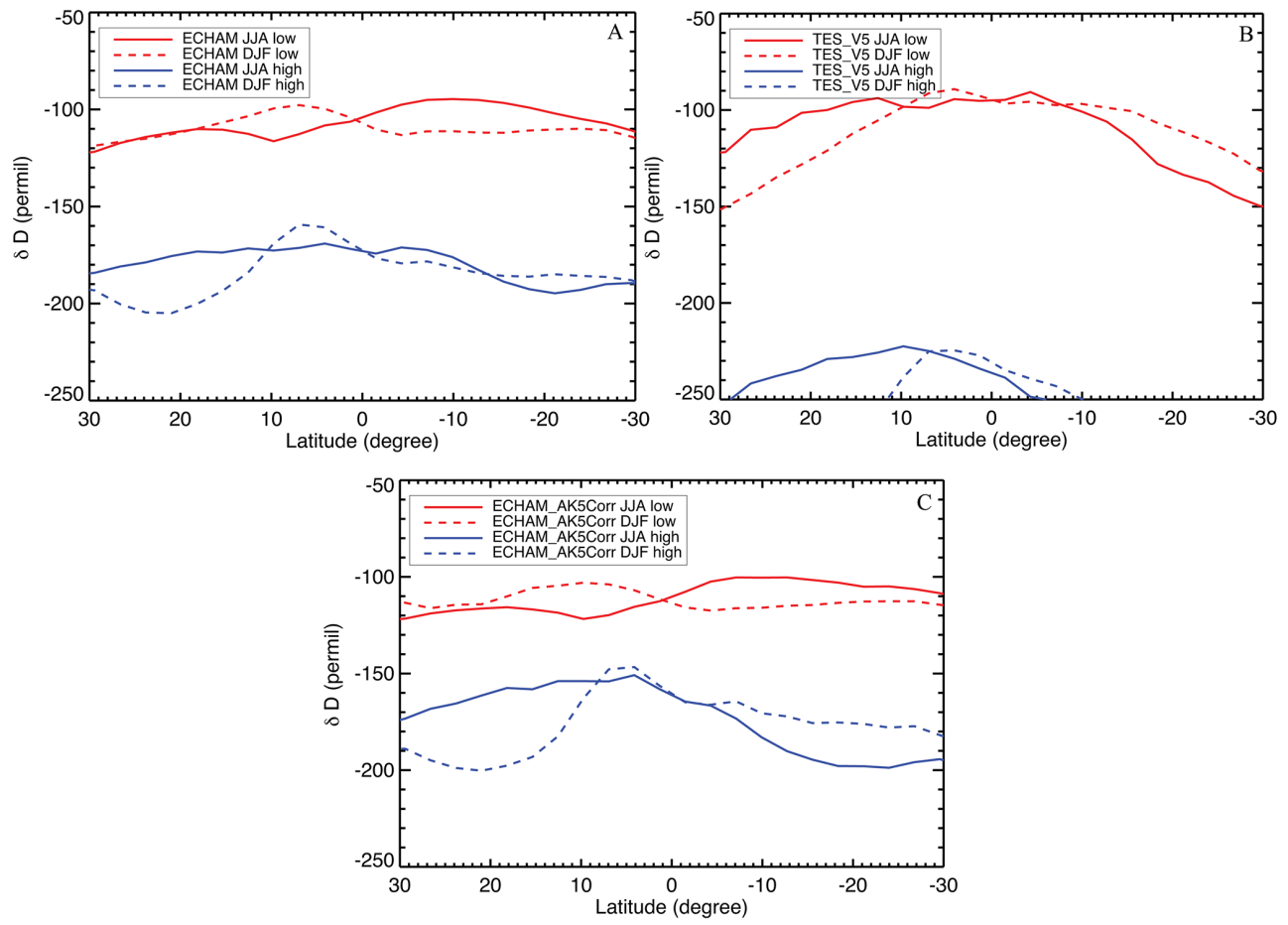

Figure 6. Latitudinal profiles between $30^{\circ} \mathrm{N}$ and $30^{\circ} \mathrm{S}$ in northern summer (JJA, solid lines) and northern winter (DJF, dashed lines) of ECHAM weighted averaged from 900 to $680 \mathrm{hPa}$ and from 618 to $425 \mathrm{hPa}$ (a), of TES 5 from 900 to $680 \mathrm{hPa}$ and from 618 to $425 \mathrm{hPa}$ (b), and of ECHAM ${ }_{\mathrm{AK} 5 \mathrm{Corr}}$ from 900 to $680 \mathrm{hPa}$ and from 618 to $425 \mathrm{hPa}$ (c). 
tudes (Yoshimura et al., 2011; Frankenberg et al., 2009) and from lower to higher altitudes (Schneider et al., 2010; Worden et al., 2007; Brown et al., 2008). Assuming that this process is exclusively temperature dependent and controlled by a moist adiabatic lapse rate, a qualitative explanation of the isotopic temperature effect over a wide temperature range is straightforward. It is instructive to check to what degree the atmosphere corresponds to this simple temperaturedependent scheme: how Rayleigh-like is the earth's atmosphere?

Temperature gradients from the surface to higher altitudes and from the tropics to mid- and high latitudes dry the corresponding air masses and lead to both lower total precipitable water (TPW) and, via the Rayleigh mechanism, to more depleted isotope values. In a pure Rayleigh distillation system, $\ln \left(\mathrm{HDO} / \mathrm{H}_{2} \mathrm{O}\right)$ is linearly related to $\ln (\mathrm{TPW})$, and the slope corresponds to the effective equilibrium fractionation, $\alpha_{\text {eff }}-1$ (Frankenberg et al., 2009; Schneider et al., 2010; Yoshimura et al., 2011). Here, $\alpha_{\text {eff }}$ refers to a mean fractionation over the entire distillation process with an "effective fractionation temperature" (Frankenberg et al., 2009; Yoshimura et al., 2011).

In the following we investigate whether the atmosphere follows such a Rayleigh distillation model. Globally, a $\ln \left(\mathrm{HDO} / \mathrm{H}_{2} \mathrm{O}\right)$ versus $\ln (\mathrm{TPW})$ plot (see Fig. $7 \mathrm{a}$ and $\mathrm{b}$ ) is dominated by the latitudinal gradient of both quantities (i.e., the latitude effect). Lower $\ln (\mathrm{TPW})$ values and more depleted isotopic values are largely organized along a gradient from lower to higher latitudes. At high $\ln (\mathrm{TPW})(>3)$, the different data sets agree rather well, but below 3, significant differences become apparent. Between $\ln (\mathrm{TPW})$ values of 2 and 3 , SCIAMACHY appears to have lower $\ln \left(\mathrm{HDO} / \mathrm{H}_{2} \mathrm{O}\right)$ values than ECHAM and TES. Below a $\ln (\mathrm{TPW})$ of 2, SCIAMACHY also displays a group of very high $\ln \left(\mathrm{HDO} / \mathrm{H}_{2} \mathrm{O}\right)$ values, which show a larger scatter and deviate strongly from the linear correlation. The ECHAM model shows two separated branches at the lower end of the global distillation chain, which corresponds to air masses over Antarctica and the Arctic (Fig. 7b). This feature is not reproduced by any available observational data set since observations in these regions are absent.

It is evident that these structures influence the linear regression lines shown in Fig. 7. The original ECHAM model simulates steeper overall slopes than observed by the satellites, mainly because the model results include strongly depleted water vapor at higher and polar latitudes, where no satellite data are available. TES $\mathrm{V5}$ data result in a steeper slope than $\mathrm{TES}_{\mathrm{V} 4}$, which again reflects the smaller latitude gradient in $\mathrm{TES}_{\mathrm{V} 4}$, and convolution with the version $4 \mathrm{AK}$ leads to a similarly low slope for $\mathrm{ECHAM}_{\mathrm{AK} 4}$. The slope for the $\mathrm{ECHAM}_{\mathrm{AK} 5}$ data set is lower than TES $\mathrm{V}_{5}$. However, both TES products disagree with ECHAM and SCIAMACHY for $\ln (\mathrm{TPW})$ lower than 2.5. The differences between data sets for lower $\ln (\mathrm{TPW})$ reflect the differences discussed in Sect. 4.1 for the latitudinal $\delta \mathrm{D}$ gradients at mid- and high latitudes. In the following we focus on the tropical region (high $\ln (\mathrm{TPW})$ ) where the latitudinal profiles are in good agreement.

In the tropics, the differences between the data sets in the $\ln \left(\mathrm{HDO} / \mathrm{H}_{2} \mathrm{O}\right)$ versus $\ln (\mathrm{TPW})$ correlation plot are smaller, but the correlation between $\ln (\mathrm{TPW})$ and the isotopes and the respective slope of this correlation is lower as well (Fig. 7c and d). These low slopes imply unrealistically high "effective" condensation temperatures for the satellite data sets (TESV5 and SCIAMACHY) and even more for the ECHAM model (up to almost $60^{\circ} \mathrm{C}$ ). Apparently, a description of the relatively small isotopic variance by a simple overall distillation process is not suitable. This is likely due to the dominance of convective activity there, which affects the isotopic composition by many large-scale (e.g., low-level humidity confluence) and sub-scale processes (e.g., entrainment/detrainment of vapor in convective systems) that are not sufficiently described by Rayleigh fractionation. The isotope amount effect in the tropics is another factor contributing to the relatively flat slope because it leads to lower $\delta$ values at higher humidity (Fig. 7d). This feature is more prominent in the V5 data set and less so in the V4 data set.

Figure $7 \mathrm{e}$ and $\mathrm{f}$ show $\ln \left(\mathrm{HDO} / \mathrm{H}_{2} \mathrm{O}\right)$ vs. $\ln (\mathrm{TPW})$ from satellites and model simulations over the Sahel region $(0-$ $\left.10^{\circ} \mathrm{E}, 15-30^{\circ} \mathrm{N}\right)$. The Sahel has been chosen because SCIAMACHY shows the best performance here and has recorded most measurements (>6000 measurements; see Frankenberg et al., 2009, allowing therefore for a more complete comparison with the TES data. The slopes from all data sets in the Sahel are relatively flat except for SCIAMACHY. This may again be related to the diverging vertical sensitivity of the different data sets. Based on a network of FTIR $\mathrm{HDO} / \mathrm{H}_{2} \mathrm{O}$ observations, Schneider et al. (2010) conclude that $\ln \left(\mathrm{HDO} / \mathrm{H}_{2} \mathrm{O}\right)$ versus $\ln (\mathrm{TPW})$ slopes are steeper in air masses close to the surface and decrease progressively with height. In our observations, the slope is highest for SCIAMACHY, which also has the highest sensitivity close to the surface. The slope is high for $\mathrm{TES}_{\mathrm{V} 4}$ and higher for TESv5, which has the lowest sensitivity in the lower troposphere. Interestingly, the slope from SCIAMACHY (0.093) is in the range of a typical Rayleigh distillation process slope, which is between 0.08 and $0.15\left(+20\right.$ to $\left.-20^{\circ} \mathrm{C}\right)$ depending on evaporation/condensation temperatures (Majoube, 1971a, b; Yoshimura et al., 2011). The SCIAMACHY slope would correspond to an effective condensation temperature of $281.8 \mathrm{~K}$. The slopes from TES ${ }_{\mathrm{V} 5}$, ECHAM, ECHAM $\mathrm{EK}_{5}$, ECHAM $_{\text {AK5Corr }}$, ECHAM $_{\text {AK5Pos }}$, and TES V5Pos correspond to $314.2,317.7,313.9,322.6,311.1$, and $325.1 \mathrm{~K}$, respectively (Fig. 1f and g).

In Figure $7 \mathrm{~h} \ln \left(\mathrm{HDO} / \mathrm{H}_{2} \mathrm{O}\right)$ vs. $\ln (\mathrm{TPW})$ scatterplots over the Sahel area are shown for all model layers from 900 to $425 \mathrm{hPa}(900,825,749,681,618,510$, and $425 \mathrm{hPa})$. Since SCIAMACHY only provides total column data, it is not included in this analysis. All slopes from single altitude layers are steeper than the slopes from the to- 

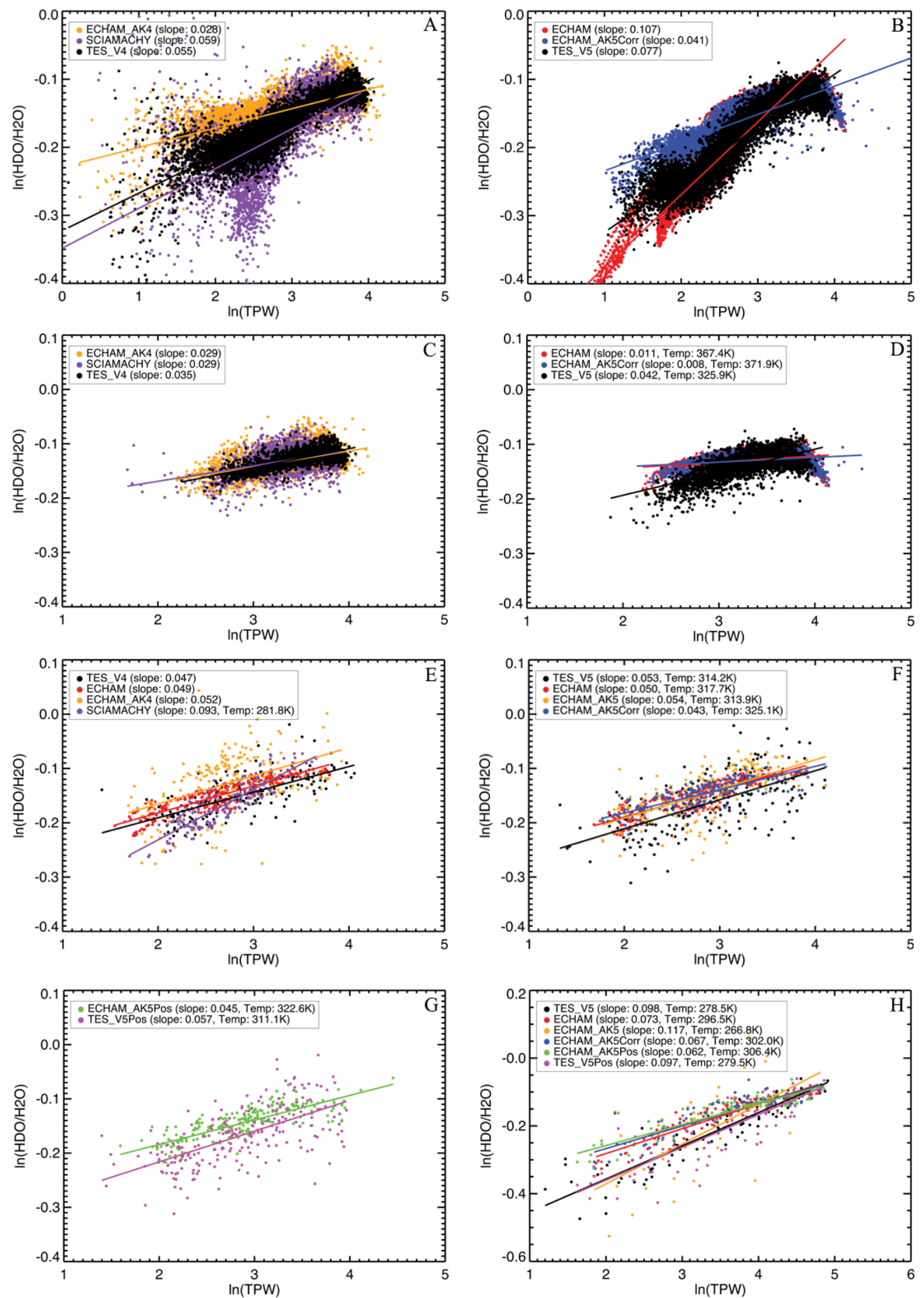

Figure 7. Correlation plot of $\ln (\mathrm{TPW}$ ) (total precipitable water derived from specific humidity) versus model simulated and satellite retrieved $\ln \left(\mathrm{HDO} / \mathrm{H}_{2} \mathrm{O}\right)$. (a, b) Global correlations. (c, d) Correlations in the tropics (30N-30S). (e, f, g, h) Correlations in the Sahel region. (a), (c), and (e) show the TES $\mathrm{V} 4$ data sets and SCIAMACHY. (b), (d), (f), (g), and (h) show the TES 5 data sets, both together with ECHAM AK $_{\text {(a), }}$ (c), and (e) are weighted averaged from 850 to $500 \mathrm{hPa}$; (b), (d), (f), and (g) are weighted averaged from 900 to $425 \mathrm{hPa}$. (h) is correlation plot at each layer from 900 to $425 \mathrm{hPa}(900,825,749,681,618,510$, and $425 \mathrm{hPa})$. 

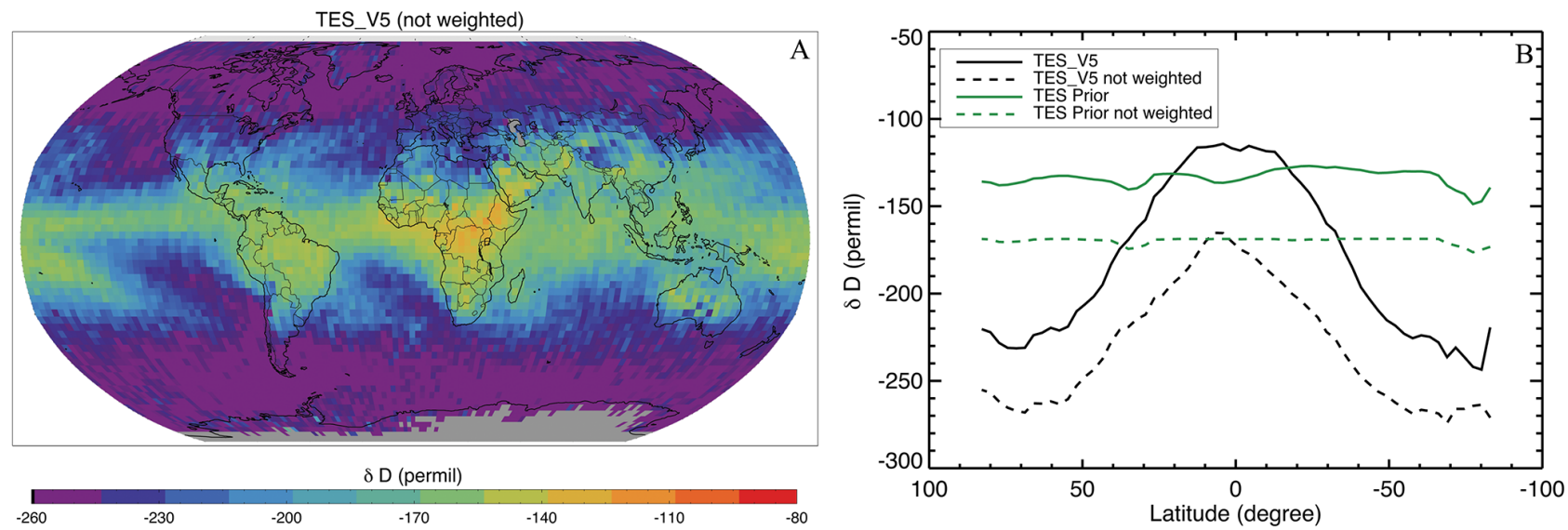

Figure 8. (a) Arithmetically averaged $\delta \mathrm{D}$ product from $\mathrm{TES}_{\mathrm{V} 5}$ for the vertical region $900-425 \mathrm{hPa}$; (b) annually averaged latitude distribution of the $\mathrm{H}_{2} \mathrm{O}$-weighted (solid lines) and arithmetically averaged (dashed lines) $\delta \mathrm{D}$ value (900-425 hPa) from TES 5 and the respective values for the prior green.

tal column $\ln \left(\mathrm{HDO} / \mathrm{H}_{2} \mathrm{O}\right)$ vs. $\ln (\mathrm{TPW})$ data. The $\mathrm{TES}_{\mathrm{V} 5}$, ECHAM, $\mathrm{ECHAM}_{\mathrm{AK} 5}$, and $\mathrm{ECHAM}_{\mathrm{AK} 5 \text { Corr }}$ slopes increase from $\sim 0.05$ to $\sim 0.08$, which lies in the range of typical Rayleigh distillation slopes. The a posteriori analysis products produce similar results to the original $\mathrm{TES}_{\mathrm{V} 5}$ and ECHAM $_{\mathrm{AKCorr}}$. The outlier data point with $\ln \left(\mathrm{HDO} / \mathrm{H}_{2} \mathrm{O}\right)$ above 0 may cause the highest slope of $\mathrm{ECHAM}_{\mathrm{AK} 5}$.

The low slopes of the $\ln \left(\mathrm{HDO} / \mathrm{H}_{2} \mathrm{O}\right)$ vs. $\ln (\mathrm{TPW})$ total column correlations imply that the total column data are inadequate to describe the Rayleigh model from the tropics to higher latitudes. We suggest using single altitude layers, although in the atmosphere there are many factors influencing this process, such as mixing of various air parcels (Gedzelman, 1988; Johnson et al., 2001), evaporation of condensate water (Smith, 1992; Galewsky et al., 2007), kinetic effects (Keith, 2000), or active convection (Smith et al., 2006; Moyer et al., 1996). Worden et al. (2007) and Brown et al. (2008) studies show that the amount effect plays an important role in the tropics. The isotopic composition of water vapor is lower than predicted by the Rayleigh condensation curve. Apparently these processes have an important influence on the isotope-concentration correlation that overrules the condensation-temperature-induced correlation.

\subsection{Weighted versus not weighted average of $\delta D$}

All $\delta \mathrm{D}$ total column data in the previous chapters were computed as averages weighted with the respective water vapor mixing ratio (see Eq. 2). This appears as a logical choice since it considers the total amount of the respective isotopologues in the atmospheric column. However, this weighted $\delta \mathrm{D}\left(\delta \mathrm{D}_{\mathrm{Col}}\right)$ is influenced by the vertical distribution of $\mathrm{H}_{2} \mathrm{O}$ and its uncertainties. Weighted this way, the $\delta \mathrm{D}_{\mathrm{Col}}$ value is biased to near-surface levels where most of the total humidity is located. This means that the variability and the respective uncertainties of low level water vapor will affect $\delta \mathrm{D}_{\mathrm{Col}}$. Here we discuss briefly the differences between $\mathrm{H}_{2} \mathrm{O}$-weighted values of $\delta \mathrm{D}_{\mathrm{Col}}$ and a simple arithmetic average (see Fig. 8).

As expected, the arithmetically averaged $\delta \mathrm{D}$ values $(900$ $425 \mathrm{hPa}$ ) are considerably lower than humidity weighted values (Fig. 8a). The difference between the two computations of $\delta \mathrm{D}$ amounts to about $60 \%$ in the tropics (Fig. 8b). The latitudinal distribution of the arithmetically averaged $\delta \mathrm{D}$ is more depleted than $\delta \mathrm{D}_{\mathrm{Col}}$, since the later is strongly determined by near-surface water vapor. The $\delta \mathrm{D}_{\mathrm{Col}}$ of TES 5 and TES prior values in the tropics show fluctuations, indicating the influence of $\mathrm{H}_{2} \mathrm{O}$ variability close to the surface. SCIAMACHY does not measure vertical profiles of $\delta \mathrm{D}$; therefore the SCIAMACHY $\delta$ D total column values shown in this paper are dominated by $\delta \mathrm{D}$ close to the surface and may additionally be influenced by the $\mathrm{H}_{2} \mathrm{O}$ variability in the vertical column of water vapor.

\section{Conclusions}

In recent years, water isotope retrievals have become available from different global satellite instruments. Here we compared the $\mathrm{HDO} / \mathrm{H}_{2} \mathrm{O}$ data from TES version 4 , TES version 5, and SCIAMACHY with each other and with largescale isotope patterns from the ECHAM model. We systematically assessed how first-order water isotope effects (temperature, latitude, altitude, continental, and amount effect) are represented in the respective remote sensing data sets.

The geographical and temporal patterns in the respective water isotopologue fields reproduced the different "classical" large-scale isotope effects to a varying degree. Our analysis confirmed the improvement of TES $\mathrm{V}_{\mathrm{V}}$ compared to $\mathrm{TES}_{\mathrm{V} 4}$ for the first-order global isotope signals investigated. Similarly, when the model results are convoluted with the

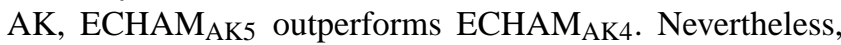
we identified a problem of ECHAM $_{\mathrm{AK} 5}$ over the Himalayas 
region. The large positive isotope anomalies were shown to be caused by a high-humidity bias of the ECHAM. A humidity correction or an a posteriori processing is necessary for model-data comparison because of cross dependence between $\mathrm{H}_{2} \mathrm{O}$ and $\delta \mathrm{D}$ in the application of the AK to the model. Furthermore, ECHAM overestimates $\delta \mathrm{D}$ values at midlatitudes compared to SCIAMACHY and TES ${ }_{\mathrm{V} 5}$, and the tropical and subtropical band of high $\delta \mathrm{D}$ values is wider in the model than in the satellite data sets. This is a common problem in many GCMs since the models tend to have a high moist bias in the tropical and subtropical regions associated with errors in cloud processes, large-scale circulation, and diffusion during water vapor transport.

When examining the seasonally varying $\delta \mathrm{D}$ signal in the tropics associated with the movement of the ITCZ, SCIA-

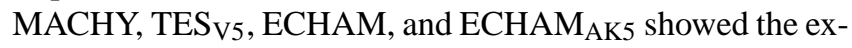
pected seasonal covariation of the latitudinal $\delta \mathrm{D}$ minima and maxima in water vapor with insolation and rainfall. Some of the isotopologue effects are difficult to identify in SCIAMACHY because of its limited coverage of large parts of the respective winter hemispheres and oceans.

We also tested to what extent the atmosphere in the different data sets can be described as a Rayleigh distillation system. The results show that the humidity-isotope correlations based on the total column values cannot be explained with a simple Rayleigh distillation model. For small regions, e.g., in the Sahel, the observations from TES ${ }_{V 5}$ and SCIAMACHY imply a more Rayleigh-type behavior than what is modeled in ECHAM. However, none of the effective condensation temperatures deduced from the observed slopes reflect pure Rayleigh condensation temperatures. This comes not as a surprise since many processes influence this condensation process, such as mixing of the air parcel, evaporation of condensate water, kinetic effects, and active convection, which are not controlled by a single effective condensation temperature. However, when we plot the vertical profiles of humidity and $\delta \mathrm{D}$, the correlation slopes from all data are close to Rayleigh condensation slopes.
As the vertical resolution of the present satellite remote sensing products is very limited, it is not possible to investigate the differences between the vertical and the horizontal dimension in more detail yet. To study this further, remote sensing data of the water isotopologues are needed that faithfully resolve single atmospheric levels. This should also help to reduce the influence of $\mathrm{H}_{2} \mathrm{O}$ distribution in the computation of total column values (humidity bias). For model and satellite comparison, however, we can use total column of $\delta \mathrm{D}$ as long as both the model and satellite are equally treated and the adequate averaging kernels is applied to the model.

One central application of existing and future water isotopologue data sets will be the evaluation of global observations and models. We suggest using the qualitative and quantitative tests carried out in this study as a benchmark for the different data products and evaluating their strengths and weaknesses. 


\section{Appendix A}
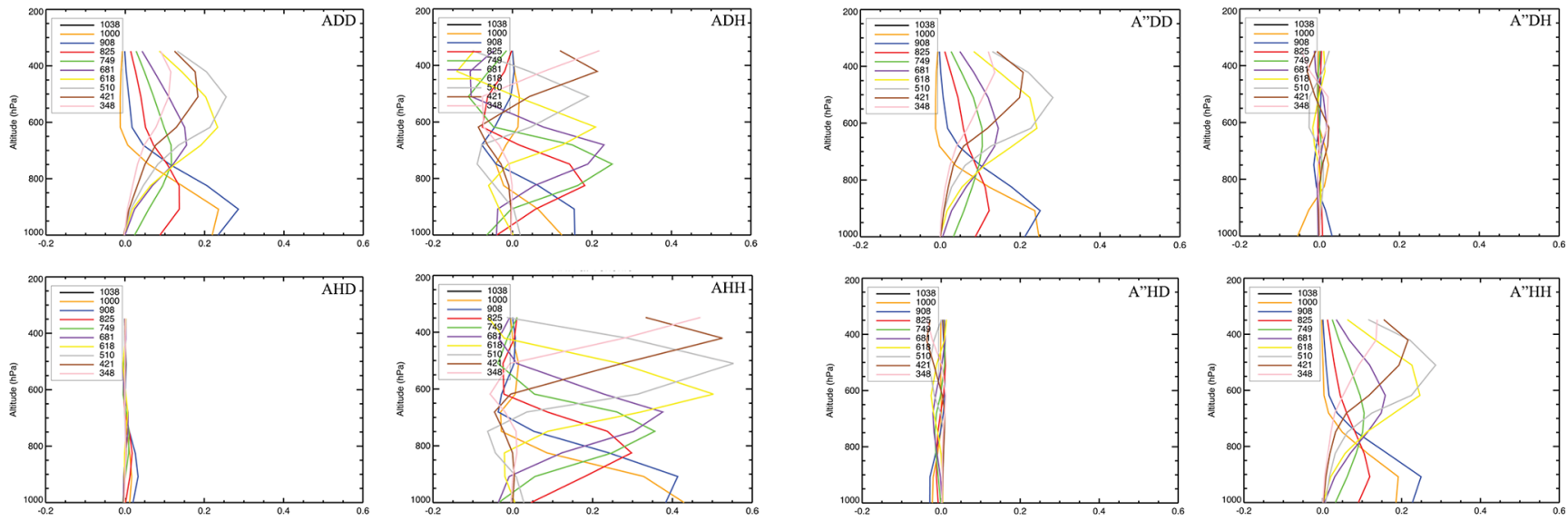

Figure A1. Averaging kernels in the $\left(\ln \left[\mathrm{H}_{2} \mathrm{O}\right], \ln [\mathrm{HDO}]\right)$ basis for $A_{\mathrm{DD}}, A_{\mathrm{DH}}, A_{\mathrm{HD}}$, and $A_{\mathrm{HH}}$, and in the $\left(\left(\ln \left[\mathrm{H}_{2} \mathrm{O}\right]+\ln \left[\mathrm{H}_{2} \mathrm{O}\right]\right) / 2, \ln [\mathrm{HDO}]-\right.$ $\left.\ln \left[\mathrm{H}_{2} \mathrm{O}\right]\right)$-proxy state after a posteriori correction $\left(A_{\mathrm{DD}}^{\prime \prime}, A_{\mathrm{DH}}^{\prime \prime}, A_{\mathrm{HD}}^{\prime \prime}, A_{\mathrm{HH}}^{\prime \prime}\right)$.

In this appendix, we present TES averaging kernels over Tenerife before applying the a posteriori correction $(A)$ and after applying the a posteriori correction $\left(A^{\prime \prime}\right)$. The vertical sensitivity of the satellite is higher for water vapor compared to HDO. This is seen from the higher averaging kernel values of $A_{\mathrm{HH}}$ than $A_{\mathrm{DD}}$. The a posteriori analysis aims for the best possible degree of consistency between $\mathrm{H}_{2} \mathrm{O}$ and $\delta \mathrm{D}$ profiles. The vertical resolution and sensitivity of the humidity ( $\mathrm{HHO}$ ) product need to be adapted to the vertical resolution and sensitivity of the isotopologue ratio product. After this a posteriori correction, the retrieved humidity and isotopologue ratio represent the same atmospheric air mass $\left(A_{\mathrm{DD}}^{\prime \prime} \approx A_{\mathrm{HH}}^{\prime \prime}\right)$. 
Acknowledgements. This study was funded by NWO (the Netherlands Organization for Scientific Research) project number ALW-GO-AO/10-11. R. A. Scheepmaker acknowledges funding from the Netherlands Space Office as part of the User Support Program Space Research under project GO-AO/16. We thank M. Schneider for a very insightful and helpful review.

Edited by: J. Joiner

\section{References}

Aggarwal, P. K., Gat, J. R., and Froehlich, K. F. O.: Isotopes in the Water Cycle: Past, Present and Future of a Developing Science, Springer, IAEA, 2007.

Back, L. E. and Bretherton, C. S.: The relationship between wind speed and precipitation in the Pacific ITCZ, J. Climate, 18, 43174328, 2005.

Bowen, G. J. and Wilkinson, B.: Spatial distribution of $\delta^{18} \mathrm{O}$ in meteoric precipitation, Geology, 30, 315-318, doi:10.1130/00917613, 2002.

Bowman, K. W., Rodgers, C. D., Kulawik, S. S., Worden, J., Sarkissian, E., Osterman, G., Steck, T., Lou, M., Eldering, A., Shephard, M., Worden, H., Lampel, M., Clough, S., Brown, P., Rinsland, C., Gunson, M., and Beer, R.: Tropospheric Emission Spectrometer: Retrieval Method and Error Analysis, IEEE T. Geosci. Remote, 44, 1297-1307, 2006.

Boesch, H., Deutscher, N. M., Warneke, T., Byckling, K., Cogan, A. J., Griffith, D. W. T., Notholt, J., Parker, R. J., and Wang, Z.: $\mathrm{HDO} / \mathrm{H}_{2} \mathrm{O}$ ratio retrievals from GOSAT, Atmos. Meas. Tech., 6, 599-612, doi:10.5194/amt-6-599-2013, 2013.

Brown, J., Simmonds, I., and Noone, D.: Modeling $\delta^{18} \mathrm{O}$ in tropical precipitation and the surface ocean for present day climate, J. Geophys. Res., 111, D05105, doi:10.1029/2004JD005611, 2006.

Brown, D., Worden, J., and Noone, D.: Comparison of atmospheric hydrology over convective continental regions using water vapor isotope measurements from space, J. Geophys. Res., 113, D15124, doi:10.1029/2007JD009676, 2008.

Conroy, J. L., Cobb, K. M., and Noone, D.: Comparison of precipitation isotope variability across the tropical Pacific in observations and SWING2 model simulations, J. Geophysical. Res.Atmos., 118, 5867-5892, doi:10.1002/jgrd.50412, 2013.

Craig, H.: Isotopic variations in meteoric waters, Science, 133, 1702-1703, 1961.

Dansgaard, W.: Stable isotopes in precipitation, Tellus, 16, 436468, 1964.

Ehhalt, D. H., Davidson, J. A., Cantrell, C. A., Friedman, I., and Tyler, S.: The kinetic isotope effect in the reaction of $\mathrm{H}_{2}$ with OH, J. Geophys. Res., 94, 9831-9836, 1989.

Frankenberg, C., Yoshimura, K., Warneke, T., Aben, I., Butz, A., Deutscher, N., Griffith, D., Hase, F., Notholt, J., Schneider, M., Schrijver, H., and Röckmann, T.: Dynamic processes governing the isotopic composition of water vapor as observed from space and ground, Science, 325, 1374-1377, doi:10.1126/science.1173791, 2009.

Frankenberg, C., Wunch, D., Toon, G., Risi, C., Scheepmaker, R., Lee, J.-E., Wennberg, P., and Worden, J.: Water vapor isotopologue retrievals from high-resolution GOSAT shortwave infrared spectra, Atmos. Meas. Tech., 6, 263-274, doi:10.5194/amt-6263-2013, 2013.

Franz, P. and Röckmann, T.: High-precision isotope measurements of $\mathrm{H}_{2}^{16} \mathrm{O}, \mathrm{H}_{2}^{17} \mathrm{O}, \mathrm{H}_{2}^{18} \mathrm{O}$, and the $\Delta^{17} \mathrm{O}$-anomaly of water vapor in the southern lowermost stratosphere, Atmos. Chem. Phys., 5, 2949-2959, doi:10.5194/acp-5-2949-2005, 2005.

Field, R. D.: Observed and modeled controls on precipitation $\delta^{18} \mathrm{O}$ over Europe: From local temperature to the Northern Annular Mode, J. Geophys. Res., 115, D12101, doi:10.1029/2009JD013370, 2010.

Galewsky, J., Strong, M., and Sharp, Z. D.: Measurements of water vapor D/ H ratios from Mauna Kea, Hawaii, and implications for subtropical humidity dynamics, Geophys. Res. Lett., 34, L22808, doi:10.1029/2007GL031330, 2007.

Gedzelman, S. D.: Deuterium in water vapor above the atmospheric boundary layer, Tellus B, 40, 134-147, 1988.

Gedzelman, S., Hindman, E., Zhang, X., Lawrence, J., Gamache, J., Black, M., Black, R., Dunion, J., and Willoughby, H.: Probing Hurricanes with stable isotopologues of rain and water vapour, Mon. Weather Rev., 131, 1112-1127, 2003.

Griffith, D.W.T, Jamie, I., Esler, M., Wilson, S.R., Parkes, S.D., Waring, C., and Bryant, G.W.: Real-time measurements of stable isotopes in water and $\mathrm{CO}_{2}$ by Fourier transform infrared spectrometry, Isot. Environ. Healt. S., 42, 9-20, doi:10.1080/10256010500503098, 2006.

Gupta, P., Noone, D., Galewsky, J., Sweeney, C., and Vaughn, B. H.: Demonstration of high-precision continuous measurements of water vapor isotopologues in laboratory and remote field deployments using wavelength-scanned cavity ring-down spectroscopy (WS-CRDS) technology, Rapid Commun. Mass Sp., 23, 25342542, doi:10.1002/rcm.4100, 2009.

Hoffmann, G., Werner, M., and Heimann, M.: Water isotope module of the ECHAM atmospheric general circulation model: A study on timescales from days to several years, J. Geophys. Res., 103, 16871-16896, 1998.

Herbin, H., Hurtmans, D., Turquety, S., Wespes, C., Barret, B., Hadji-Lazaro, J., Clerbaux, C., and Coheur, P.-F.: Global distributions of water vapour isotopologues retrieved from IMG/ADEOS data, Atmos. Chem. Phys., 7, 3957-3968, doi:10.5194/acp-7-3957-2007, 2007.

Herbin, H., Hurtmans, D., Clerbaux, C., Clarisse, L., and Coheur, P.-F.: $\mathrm{H}_{2}^{16} \mathrm{O}$ and HDO measurements with IASI/MetOp, Atmos. Chem. Phys., 9, 9433-9447, doi:10.5194/acp-9-9433-2009, 2009.

Herman, R. L., Cherry, J. E., Young, J., Welker, J. M., Noone, D., Kulawik, S. S., and Worden, J.: Aircraft validation of Aura Tropospheric Emission Spectrometer retrievals of $\mathrm{HDO} / \mathrm{H}_{2} \mathrm{O}$, Atmos. Meas. Tech., 7, 3127-3138, doi:10.5194/amt-7-3127-2014, 2014.

Jo, K-N., Woo, K. S., Yi, S., Yang, D. Y., Lim, H. S., Wang, Y., Cheng, H., and Edwards, R. L.: Mid-latitude interhemispheric hydrologic seesaw over the past 550,000 yr, Nature, 508, 378382, doi:10.1038/nature13076, 2014

Johnson, D. G., Jucks, K. W., Traub, W. A., and Chance, K. V.: Isotopic composition of stratospheric water vapor: Implications for transport, J. Geophys. Res., 106, 12219-12226,2001.

Jouzel, J., Alley, R. B., Cuffey, K. M., Dansgaard, W., Grrotes, P., Hoffmann, G., Johnsen, S. J., Koster, R. D., Peel, D., Shuman, C. A., Stievenard, M., Stuiver, M., and White, J.: Validity of the 
temperature reconstruction from water isotopes in ice cores, J. Geophys. Res., 102, 26471-26487, 1997.

Keith, D. W.: Stratosphere-troposphere exchange: Inferences from the isotopic composition of water vapor, J. Geophys. Res., 105, 15167-15173, 2000.

Kuang, Z., Toon, G. C., Wennberg, P. O., and Yung, Y. L.: Measured $\mathrm{HDO} / \mathrm{H}_{2} \mathrm{O}$ ratios across the tropical tropopause, Geophys. Res. Lett., 30, 1372, doi:10.1029/2003GL017023, 2003.

Kurita, N., Noone, D., Risi, C., Schmidt, G. A., Yamada, H., and Yoneyama, K.: Intraseasonal isotopic variation associated with the Madden-Julian Oscillation, J. Geophys. Res., 116, D24101, doi:10.1029/2010JD015209, 2011.

Lacour, J.-L., Risi, C., Clarisse, L., Bony, S., Hurtmans, D., Clerbaux, C., and Coheur, P.-F.: Mid-tropospheric $\delta \mathrm{D}$ observations from IASI/MetOp at high spatial and temporal resolution, Atmos. Chem. Phys., 12, 10817-10832, doi:10.5194/acp12-10817-2012, 2012.

Lawrence, J. R., Gedzelman, S. D., Gamache, J., and Black, M.: Stable isotopologue ratios: Hurricane Olivia, J. Atmos. Chem., 41, 67-82, 2002.

Lawrence, J. R., Gedzelman, S. D., Dexheimer, D., Cho, H. K., Carrie, G. D., Gasparini, R., Anderson, C. R., Bowman, K. P., and Biggerstaff, M. I.: Stable isotopic composition of water vapor in the tropics, J. Geophys. Res., 109, D06115, doi:10.1029/2003JD004046, 2004.

Lee, J., Worden, J., Noone, D., Bowman, K., Eldering, A., LeGrande, A., Li, J.-L. F., Schmidt, G., and Sodemann, H.: Relating tropical ocean clouds to moist processes using water vapor isotope measurements, Atmos. Chem. Phys., 11, 741-752, doi:10.5194/acp-11-741-2011, 2011.

Lee, J.-E. and Fung, I.: "Amount-effect" of water isotopes and quantitative analysis of post- condensation processes, Hydrol. Process., 22, 1-8, doi:10.1002/hyp.6637, 2007

Lee, X., Sargent, S., Smith, R., and Tanner, B.: In situ measurement of the water vapor ${ }^{18} \mathrm{O} /{ }^{16} \mathrm{O}$ isotope ratio for atmospheric and ecological applications, Am. Meteorol. Soc., 22, 555-565, 2005.

Lossow, S., Steinwagner, J., Urban, J., Dupuy, E., Boone, C. D., Kellmann, S., Linden, A., Kiefer, M., Grabowski, U., Glatthor, N., Höpfner, M., Röckmann, T., Murtagh, D. P., Walker, K. A., Bernath, P. F., von Clarmann, T., and Stiller, G. P.: Comparison of HDO measurements from Envisat/MIPAS with observations by Odin/SMR and SCISAT/ACE-FTS, Atmos. Meas. Tech., 4, 1855-1874, doi:10.5194/amt-4-1855-2011, 2011.

Majoube, M.: Oxygen-18 and deuterium fractionation between water and steam, J. Chim. Phys., 68, 1423-1436, 1971 (in French).

Majoube, M.: Fractionation in O-18 between ice and water vapor, J. Chim. Phys., 68, 625-636, 1971 (in French).

Moyer, E. J., Irion, F. W., Yung, Y. L., and Gunson, M. R.: ATMOS stratospheric deuterated water and implications for tropospherestratosphere transport, Geophys. Res. Lett., 23, 2385-2388, 1996.

Noone, D. and Simmonds, I.: Associations between $\delta^{18} \mathrm{O}$ of water and climate parameters in a simulation of atmospheric circulation for 1979-95, J. Clim., 15, 3150-3169, 2002.

Oort, A. H. and Yienger, J. J.: Observed interannual variability in the Hadley circulation and its connection to ENSO, Am. Meteorolog. Soc., 9, 2751-2767, 1996.

Payne, V. H., Noone, D., Dudhia, A., Piccolo, C., and Grainger, R. G.: Global satellite measurements of HDO and implications for understanding the transport of water vapor into the stratosphere. Q. J. Roy. Meteor. Soc., 133, 1459-1471, 2007.

Pommier, M., Lacour, J.-L., Risi, C., Bréon, F. M., Clerbaux, C., Coheur, P.-F., Gribanov, K., Hurtmans, D., Jouzel, J., and Zakharov, V.: Observation of tropospheric dD by IASI over western Siberia: comparison with a general circulation model, Atmos. Meas. Tech., 7, 1581-1595, doi:10.5194/amt-7-1581-2014, 2014.

Risi, C,., Bony, S., and Vimeux, F.: Influence of convective processes on the isotopic composition $\left(\delta^{18} \mathrm{O}\right.$ and $\left.\delta \mathrm{D}\right)$ of precipitation and water vapor in the tropics: 2. Physical interpretation of the amount effect, J. Geophys. Res., 113, D19306, doi:10.1029/2008JD009943, 2008.

Risi, C., Bony, S., Vimeux, F., and Jouzel, J.: Water-stable isotopes in the LMDZ4 general circulation model: Model evaluation for present-day and past climates and application to climatic interpretation of tropical isotopic records, J. Geophys. Res., 115, D12118, doi:10.1029/2009JD013255, 2010.

Risi, C., Noone, D., Worden, J., Frankenberg, C., Stiller, G., Kiefer, M., Funke, B., Walker, K., Bernath, P., Schneider, M., Wunch, D., Sherlock, V., Deuscher, N., Griffith, D., Wennberg, P. O., Strong, K., Smale, D., Mahieu, E., Barthlott, S., Hase, F., García, O., Notholt, J., Warneke, T., Toon, G., Sayres, D., Bony, S., Lee, J., Brown, D., Uemura, R., and Sturm, C.: Processevaluation of tropospheric humidity simulated by general circulation models using water vapor isotoplogues: 1 . Comparison between models and observations, J. Geophys. Res., 117, D05303, doi:10.1029/2011JD016621, 2012a.

Risi, C., Noone, D., Worden, J., Frankenberg, C., Stiller, G., Kiefer, M., Funke, B., Walker, K., Bernath, P., Schneider, M., Bony, S., Lee, J., Brown, D., and Sturm, C.: Process-evaluation of tropospheric humidity simulated by general circulation models using water vapor isotopic observations: 2. Using isotopic diagnostics to understand the mid and upper tropospheric moist bias in the tropics and subtropics, J. Geophys. Res., 117, D05304, doi:10.1029/2011JD016623, 2012b.

Risi, C., Noone, D., Frankenberg, C., and Worden, J.: Role of continental recycling in intraseasonal variations of continental moisture as deduced from model simulations and water vapor isotopic measurements, Water Resour. Res., 49, 4136-4156, doi:10.1002/wrcr.20312, 2013.

Rodgers, C. D.: Inverse Methods for Atmospheric Sounding: Theory and Practice, World Sci., River Edge, N. J., 2000.

Rozanski, K.: Deuterium and oxygen-18 in European groundwaterlinks to atmospheric circulation in the past, Chem. Geol., 52, 349-363, 1985.

Samuel-Crow, K. E., Galewsky, J., Hardy, D. R., Sharp, Z. D., Worden, J., and Braun, C.: Upwind convective influences on the isotopic composition of atmospheroc water vapor over the tropical Andes, J. Geophys. Res.-Atmos., 119, 1-13, doi:10.1002/2014JD021487, 2014

Scheepmaker, R. A., Frankenberg, C., Galli, A., Butz, A., Schrijver, H., Deutscher, N. M., Wunch, D., Warneke, T., Fally, S., and Aben, I.: Improved water vapour spectroscopy in the $4174-4300 \mathrm{~cm}^{-1}$ region and its impact on SCIAMACHY $\mathrm{HDO} / \mathrm{H}_{2} \mathrm{O}$ measurements, Atmos. Meas. Tech., 6, 879-894, doi:10.5194/amt-6-879-2013, 2013.

Schmidt, G. A., Hoffmann, G., Shindell, D. T., and Hu, Y.: Modeling atmospheric stable water isotopes and the po- 
tential for constraining cloud processes and stratospheretroposphere water exchange, J. Geophys. Res., 110, D21314, doi:10.1029/2005JD005790, 2005.

Schmidt, G. A., LeGrande, A. N., and Hoffmann, G.: Water isotope expressions of intrinsic and forced variability in a coupled ocean-atmosphere model, J. Geophys. Res., 112, D10103, doi:10.1029/2006JD007781, 2007.

Schneider, M. and Hase, F.: Optimal estimation of tropospheric $\mathrm{H}_{2} \mathrm{O}$ and $\delta \mathrm{D}$ with IASI/METOP, Atmos. Chem. Phys., 11, 11207-11220, doi:10.5194/acp-11-11207-2011, 2011.

Schneider, M., Hase, F., and Blumenstock, T.: Ground-based remote sensing of $\mathrm{HDO} / \mathrm{H}_{2} \mathrm{O}$ ratio profiles: introduction and validation of an innovative retrieval approach, Atmos. Chem. Phys., 6, 4705-4722, doi:10.5194/acp-6-4705-2006, 2006.

Schneider, M., Yoshimura, K., Hase, F., and Blumenstock, T.: The ground-based FTIR network's potential for investigating the atmospheric water cycle, Atmos. Chem. Phys., 10, 3427-3442, doi:10.5194/acp-10-3427-2010, 2010.

Schneider, M., Barthlott, S., Hase, F., González, Y., Yoshimura, K., García, O. E., Sepúlveda, E., Gomez-Pelaez, A., Gisi, M., Kohlhepp, R., Dohe, S., Blumenstock, T., Wiegele, A., Christner, E., Strong, K., Weaver, D., Palm, M., Deutscher, N. M., Warneke, T., Notholt, J., Lejeune, B., Demoulin, P., Jones, N., Griffith, D. W. T., Smale, D., and Robinson, J.: Ground-based remote sensing of tropospheric water vapour isotopologues within the project MUSICA, Atmos. Meas. Tech., 5, 3007-3027, doi:10.5194/amt5-3007-2012, 2012.

Smith, R. B.: Deuterium in North Atlantic storm tops, J. Atmos. Sci., 49, 2041-2057, 1992.

Smith, J. A., Ackerman, A. S., Jensen, E. J., and Toon, O. B.: Role of deep convection in establishing the isotopic composition of water vapor in the tropical transition layer, Geophys. Res. Lett., 33, L06812, doi:10.1029/2005GL024078, 2006.

Steinwagner, J., Milz, M., von Clarmann, T., Glatthor, N., Grabowski, U., Höpfner, M., Stiller, G. P., and Röckmann, T.: HDO measurements with MIPAS, Atmos. Chem. Phys., 7, 26012615, doi:10.5194/acp-7-2601-2007, 2007.

Steinwagner, J., Fueglistaler, S., Stiller, G., von Clarmann, T., Kiefer, M., Borsboom, P. P., van Delden, A., and Röckmann, T.: Tropical dehydration processes constrained by the seasonality of stratospheric deuterated water, Nat. Geosci., 3, 262-266, doi:10.1038/ngeo822, 2010.

Sturm, P. and Knohl, A.: Water vapor $\delta^{2} \mathrm{H}$ and $\delta^{18} \mathrm{O}$ measurements using off-axis integrated cavity output spectroscopy, Atmos. Meas. Tech., 3, 67-77, doi:10.5194/amt-3-67-2010, 2010.

Uemura, R., Matsui, Y., Yoshimura, K., Motoyama, H., and Yoshida, N.: Evidence of deuterium excess in water vapor as an indicator of ocean surface conditions, J. Geophys. Res., 113, D19114, doi:10.1029/2008JD010209, 2008.

Uppala, S. M., Kållberg, P. W., Simmons, A. J., Andrae, U., da costa Bechtold, V., Fiorino, M., Gibson, K., Haseler, J., Hernandez, A., Kelly, G. A., Li, X., Onogi, K., Saarinen, S., Sokka, N., Allan, R. P., Andersson, E., Arpe, K., Balmaseda, M. A., Beljaars, A. C. M., van de Berg, L., Bidlot, J., Bormann, N., Caires, S., Chevallier, F., Dethof, A., Dragosavac, M., Fisher, M., Fuentes, M., Hagemann, S., Hólm, E., Hoskins, B. J., Isaksen, L., Janssen, P. A. E. M., Jenne, R., Mcnally, A. P., Mahfouf, J.-F., Morcrette, J.-J., Rayner, N. A., Saunders, R. W., Simon, P., Sterl, A., Trenberth, K. E., Untch, A., Vasiljevic, D., Viterbo, P., and Woollen,
J.: The ERA-40 re-analysis, Q. J. Roy. Meteor. Soc., 131, 29613012, doi:10.1256/qj.04.176, 2005.

Waliser, D. E. and Gautier, C.: A satellite-derived climatology of the ITCZ, J. Climate, 6, 2162-2174, 1993.

Wang, L., Caylor, K. K., and Dragoni, D.: On the calibration of continuous, high-precision $\delta^{18} \mathrm{O}$ and $\delta^{2} \mathrm{H}$ measurements using an off-axis integrated cavity output spectrometer, Rapid Commun. Mass Sp., 23, 530-536, doi:10.1002/rcm.3905, 2009.

Webster, C. R. and Heymsfield, J.: Water Isotope Ratios D/H, ${ }^{18} \mathrm{O} /{ }^{16} \mathrm{O},{ }^{17} \mathrm{O} /{ }^{16} \mathrm{O}$ in and out of Clouds Map Dehydration Pathways, Sciencemag, 302, 1742-1745, 2003.

Werner, M., Langebroek, P. M., Carlsen, T., Herold, M., and Lohmann, G.: Stable water isotopes in the ECHAM5 general circulation model: Toward high-resolution isotope modeling on a global scale, J. Geophys. Res., 116, D15109, doi:10.1029/2011JD011, 20111.

Wiegele, A., Schneider, M., Hase, F., Barthlott, S., García, O. E., Sepúlveda, E., González, Y., Blumenstock, T., Raffalski, U., Gisi, M., and Kohlhepp, R.: The MUSICA MetOp/IASI $\mathrm{H}_{2} \mathrm{O}$ and $\delta \mathrm{D}$ products: characterisation and long-term comparison to NDACC/FTIR data, Atmos. Meas. Tech., 7, 2719-2732, doi:10.5194/amt-7-2719-2014, 2014.

Worden, J., Kulawik, S. S., Shephard, M. W., Clough, S. A., Worden, H., Bowman, K., and Goldman, A.: Predicted errors of tropospheric emission spectrometer nadir retrievals from spectral window selection, J. Geophys. Res., 109, D09308, doi:10.1029/2004JD004522, 2004.

Worden, J., Bowman, K., Noone, D., Beer, R., Clough, S., Eldering, A., Fisher, B., Goldman, A., Gunson, M., Herman, R., Kulawik, S. S., Lampel, M., Luo, M., Osterman, G., Rinsland, C., Rodgers, C., Sander, S., Shephard, M., and Worden, H.: Tropospheric emission spectrometer observation of the tropospheric $\mathrm{HDO} / \mathrm{H}_{2} \mathrm{O}$ ratio: estimation approach and characterization, J. Geophys. Res., 111, D16309, doi:10.1029/2005JD006606, 2006.

Worden, J., Noone, D., and Bowman, K.: Importance of rain evaporation and continental convection in the tropical water cycle, Nature, 445, 528-532, doi:10.1038/nature05508, 2007.

Worden, J., Noone, D., Galewsky, J., Bailey, A., Bowman, K., Brown, D., Hurley, J., Kulawik, S., Lee, J., and Strong, M.: Estimate of bias in Aura TES HDO/ $\mathrm{H}_{2} \mathrm{O}$ profiles from comparison of TES and in situ $\mathrm{HDO} / \mathrm{H}_{2} \mathrm{O}$ measurements at the Mauna Loa observatory, Atmos. Chem. Phys., 11, 4491-4503, doi:10.5194/acp-11-4491-2011, 2011.

Worden, J., Kulawik, S., Frankenberg, C., Payne, V., Bowman, K., Cady-Peirara, K., Wecht, K., Lee, J.-E., and Noone, D.: Profiles of $\mathrm{CH}_{4}, \mathrm{HDO}, \mathrm{H}_{2} \mathrm{O}$, and $\mathrm{N}_{2} \mathrm{O}$ with improved lower tropospheric vertical resolution from Aura TES radiances, Atmos. Meas. Tech., 5, 397-411, doi:10.5194/amt-5-397-2012, 2012.

Wu, X., Liang, X.-Z., and Zhang, G. J.: Seasonal migration of ITCZ precipitation across the equator: Why can't GCMs simulate it?, Geophys. Res. Lett., 30, 1824, doi:10.1029/2003GL017198, 2003.

Wunch, D., Toon, G. C., Wennberg, P. O., Wofsy, S. C., Stephens, B. B., Fischer, M. L., Uchino, O., Abshire, J. B., Bernath, P., Biraud, S. C., Blavier, J.-F. L., Boone, C., Bowman, K. P., Browell, E. V., Campos, T., Connor, B. J., Daube, B. C., Deutscher, N. M., Diao, M., Elkins, J. W., Gerbig, C., Gottlieb, E., Griffith, D. W. T., Hurst, D. F., Jiménez, R., Keppel-Aleks, G., Kort, E. A., Macatangay, R., Machida, T., Matsueda, H., Moore, F., Morino, 
I., Park, S., Robinson, J., Roehl, C. M., Sawa, Y., Sherlock, V., Sweeney, C., Tanaka, T., and Zondlo, M. A.: Calibration of the Total Carbon Column Observing Network using aircraft profile data, Atmos. Meas. Tech., 3, 1351-1362, doi:10.5194/amt3-1351-2010, 2010.

Yoshimura, K., Kanamitsu, M., Noone, D., and Oki, T.: Historical isotope simulation using Reanalysis atmospheric data, J. Geophys. Res., 113, D19108, doi:10.1029/2008JD010074, 2008.

Yoshimura, K., Frankenberg, C., Lee, J., Kanamitsu, M., Worden, J., and Röckmann, T.: Comparison of an isotopic atmospheric general circulation model with new quasi-global satellite measurements of water vapor isotopologues, J. Geophys. Res., 116, D19118, doi:10.1029/2011JD016035, 2011.
Zakharov, V. I., Imasu, R., Gribanov, K. G., Hoffmann, G., and Jouzel, J.: Latitudinal distribution of the deuterium to hydrogen ratio in the atmosphere water vapor retrieved from IMG/ADEOS data, Geophys. Res. Lett., 31, L12104, doi:10.1029/2004GL019433, 2004.

Zhang, L., Jacob, D. J., Liu, X., Logan, J. A., Chance, K., Eldering, A., and Bojkov, B. R.: Intercomparison methods for satellite measurements of atmospheric composition: application to tropospheric ozone from TES and OMI, Atmos. Chem. Phys., 10, 4725-4739, doi:10.5194/acp-10-4725-2010, 2010. 